\title{
MITIGATION OF SUB-SURFACE CRACK PROPAGATION IN RAILROAD RAILS BY LASER SURFACE MODIFICATION*
}

R. J. DiMelfi 1 , P. G. Sanders ${ }^{3}$, B. Hunter ${ }^{2}$, J. A. Eastman ${ }^{3}$, K. J. Sawley ${ }^{4}$, K. Leong ${ }^{2}$ and J. M. Kramer ${ }^{1}$

\author{
1 Reactor Engineering \\ 2Technology Development \\ 3 Materials Science Division \\ Argonne National Laboratory \\ 9700 S. Cass Ave. \\ Argonne, IL 60439 \\ ${ }^{4}$ Association of American Railroads \\ Research and Test Department \\ D.C. Bcx 11130 \\ Pueblo, CO 81001
}

October 1997

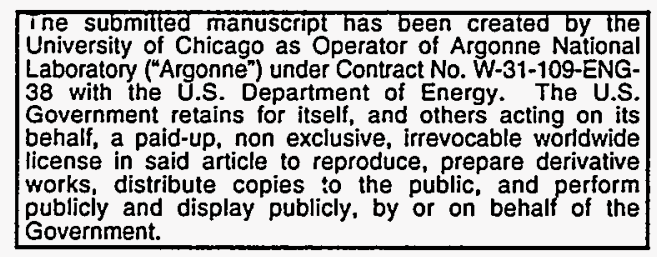

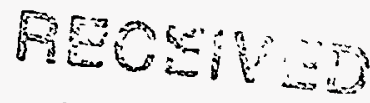

ก0บ 19997

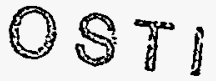

\section{DISTREUTION OF THS DOCUMETT IS UNLITFE}
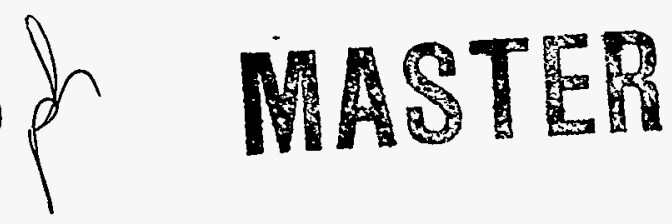

Submitted to the International Conference on Metallurgical Coatings and Thin Films, San Diego, CA, April 21-25, 1997 and also to the journal Surface and Coatings Technology.

*This work is supported by the Division of Materials Sciences, Office of Basic Energy Sciences of DOE, under contract No. W-31-109-ENG-38 and by the Association of American Railroads under WFO Contract $85 \mathrm{G} 23$. 


\section{DISCLAIMER}

This report was prepared as an account of work sponsored by an agency of the United States Government. Neither the United States Government nor any agency thereof, nor any of their employees, makes any warranty, express or implied, or assumes any legal liability or responsibility for the accuracy, completeness, or usefulness of any information, apparatus, product, or process disclosed, or represents that its use would not infringe privately owned rights. Reference herein to any specific commercial product, process, or service by trade name, trademark, manufacturer, or otherwise does not necessarily constitute or imply its endorsement, recommendation, or favoring by the United States Government or any agency thereof. The views and opinions of authors expressed herein do not necessarily state or reflect those of the United States Government or any agency thereof. 


\section{DISCLAMIER}

Portions of this document may be illegible in electronic image products. Images are produced from the best available original document 


\title{
MITIGATION OF SUB-SURFACE CRACK PROPAGATION IN RAILROAD RAILS BY LASER SURFACE MODIFICATION ${ }^{\dagger}$
}

\author{
R.J. DiMelfi, P.G. Sanders, B. Hunter*, J.A. Eastman, K.J. Sawley*, K. H. Leong \\ and J.M. Kramer
}

\begin{abstract}
Argonne National Laboratory
9700 S. Cass Avenue

Argonne, IL 60439

${ }^{\ddagger}$ Current Address, Lightpath

6820 Academy Parkway East, NE

Albuquerque, NM 87109

*Association of American Railroads

Research and Test Department

P.O. Box 11130

Pueblo, CO 81001
\end{abstract}

August 20, 1997

'This paper was presented at the 1997 International Conference on Metallurgical Coatings and Thin Films, Session E1, held April 21-25, 1997, Town and Country Hotel, San Diego, CA

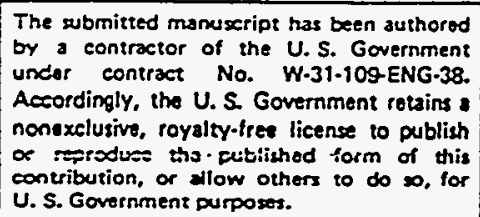

U.S. Government purposes.

Please send correspondence to:

Dr. R.J. DiMelfi

Re-208

Argonne National Laboratory

9700 S. Cass Ave.

Argonne, IL 60439

(630) 252-3736 (phone)

(630) 252-3075 (FAX)

dimelfi@anl.gov

Manuscript submitted for publication in Surface and Coatings Technology 


\title{
MITIGATION OF SUB-SURFACE CRACK PROPAGATION IN RAILROAD RAILS BY LASER SURFACE MODIFICATION
}

\begin{abstract}
We address the mitigation of sub-surface crack propagation in railroad rails via laser surface modification. The goal is to reduce the shear forces from rail-wheel friction, which contribute significantly to the nucleation and propagation of cracks in the sub-surface region at rail gage corners. Microhardness scans and tensile tests were performed on samples from cross-sections of unused and heavily used rail heads. The results of these tests indicate that the severe cyclic plastic deformation that occurs at the gage corners, during service, significantly hardens the sub-surface region there, which leads to cracking. Laser glazing, the rapid melting and rapid solidification of a thin surface layer, was used to reduce the friction coefficient of rail steel. The advantages of this process are that specific regions of the rail surface can be targeted; the treatment does not wash away as the currently used liquid lubricants do; it is more environmentally sound than liquid lubricants; and it can be applied in service, during re-work or during rail fabrication. Laser processing was conducted at Argonne National Laboratory's Laser Applications Laboratory, using a $1.6 \mathrm{~kW}$ Nd:YAG laser. Preliminary glazing treatments, involving a single pass of the laser beam over the surface of a rail head, produced a thin $(<100 \mu \mathrm{m})$ glazed surface layer, intimately bonded to a martensitic heat-affected-zone that is, itself, well bonded to the pearlitic rail-steel substrate. The glazed layer possesses an unfamiliar microstructure. The microhardness (Vickers) of the glazed layer is $\mathrm{H}_{\mathrm{V}} 800$, while that of the heat-affected-zone and substrate are $\mathrm{H}_{\mathrm{V}} 840$ and $\mathrm{H}_{\mathrm{V}} 300$, respectively. A number of laser treatments were conducted on AISI 1080 steel plates, similar to rail steel, from which friction samples were extracted. Treatments involving a single pass of the laser beam produced a similar glazed layer $\left(\mathrm{H}_{\mathrm{V}} 689\right)$ intimately bonded to an untempered martensite heataffected-zone $\left(\mathrm{H}_{\mathrm{V}} 1072\right)$, which is well-bonded to the substrate $\left(\mathrm{H}_{\mathrm{V}} 300\right)$. Treatments involving multiple passes of the laser beam, overlapping each other but rastered to produce a wider glazed region on the steel plates, produced a similar glazed layer $\left(\mathrm{H}_{\mathrm{V}} 655\right)$ bonded to a tempered martensite heat-affected-zone $\left(\mathrm{H}_{\checkmark}, 470\right)$. Tempering occurs because each subsequent laser pass tempers the martensite produced by the previous one. Static "block-on-ring" friction experiments performed at Falex Corporation on a variety of laser treated surfaces, involving both single and multiple pass treatments, showed reductions in the friction coefficient by about $25 \%$ relative to untreated surfaces at loads corresponding to prototypic rail service loads. X-ray scans of treated surfaces were inconclusive regarding the nature of the glazed layer. We laser-glazed two areas on the top surface of a six-foot length of rail with multiple pass treatments, one with adjacent passes overlapping, and one with adjacent passes separated by $1 \mathrm{~mm}$. Each treated area was $\sim 4$ inches long, in the direction of travel along the rail and $\sim 0.75$ in. wide. Friction measurements were made on these surfaces at the Association of American Railroad's Cyclic Rolling-Sliding Wear Machine after they were subjected to 20,000 run-in cycles at loads prototypic of service. The laser treatments remained intact after these cycles. Reductions of friction coefficient of $\sim 40 \%$, relative to untreated surfaces, were observed, which corresponds to a reduction in the calculated mixed mode crack propagation rate by $\sim 79 \%$.
\end{abstract}




\section{Mitigation of Sub-surface Crack Propagation in Railroad Rails \\ by Laser Surface Modification}

\section{Introduction}

The problem of concern to the railroads that is addressed in this paper is the occurrence of subsurface cracks ("shell defects") that propagate parallel to the rail surface in the direction of train travel [1]. As shown schematically in Fig. 1, these cracks are located primarily in the gage corner of the rail. The problem they pose is exacerbated at curves in the track. Serious consequences (possible derailment) can result when the cracks turn up or down, i.e. perpendicular to the direction of travel ("detail fracture"). The cause of this cracking is the severe cyclic loading to which the rail is subjected during normal service in supporting passing locomotives and train cars. The loads can be a combination of normal and shear forces, the latter produced by rail-wheel friction, which can be particularly severe at curves in the track. In fact, it was found by Gervais and McQueen [2] that without shear, prototypic normal loads were not sufficient alone to nucleate shell defects, even after several rail lifetimes of cyclic loading. Hence, shear is important, which is why the cracks are observed primarily at gage comers and why the problem is worsened at curves.

Obviously, a solution to the problem just described would be to reduce rail-wheel friction at locations of concern on the rail. Recognizing this, the railroads currently apply liquid lubricants to rails via mechanized systems activated as trains pass such locations. However, liquid lubricants have problems associated with them. They can be washed away in the rain, they are not entirely environmentally sound, and there is an inherent problem with regard to controlling where the lubricant is specifically applied to the rail surface. For reasons of traction, one does not want the lubricant to be applied to the top surface of the rail. To directly address these issues while reducing rail-wheel friction, we propose the application of a solid-state lubricant via rail surface modification. This approach will allow one to accurately target the location of the treatment, which can be applied in service as a rework procedure, and which may even be applicable during rail fabrication. Any such treatment must be durable, capable of sustaining heavy loads, economical and commercially available.

We suggest that laser glazing, the rapid solidification of a very thin melt layer produced on the rail surface by a moving laser beam, is an appropriate treatment for this purpose. Such treatments are known to produce ultra-fine non-equilibrium structures and even amorphous films when solidification rates are very high. There is reason to believe [3] that the presence of such films can reduce the coefficient of friction in rail steels. Strutt et al. [4] has improved the behavior of tool steels with such treatments and Hetzner [5] is achieving significant improvements in steel bearings via laser glazing. For a review of the parameters and effects of laser glazing, see the paper by Singh [6], who has also worked extensively in this field. In this paper, we will present the results of our research in laser glazing of rail steels and actual sections of railroad rail. We will discuss rail steel mechanical behavior, surface modification issues and laser processing, microstructural and microhardness changes, the observation of non-equilibrium phases, the resulting changes in friction coefficient and their relation to crack propagation. 


\section{Rail-steel Mechanical Behavior}

Hardness and Deformation Behavior: The rail-steel mechanical behavior, particularly its deformation behavior, is relevant to the cracking issue of concern. Crack nucleation and propagation in ductile metals during cyclic loading can be related to the accumulation of deformation debris (dislocations) in localized regions, and the inability of the material to mitigate loads in that region by further plastic flow [7]. In the case of railroad rails subjected to normal and shear loads, this debris can accumulate in the sub-surface region, resulting in crack nucleation. The nucleated crack advances with subsequent cycling as the plasticity becomes exhausted in a localized region ahead of the crack tip. The accumulation of dislocation debris in a region, and hence the propensity for crack nucleation there, is reflected in the mechanical properties of that region. To explore this, we have probed the mechanical properties of actual rail steel in two ways, illustrated schematically in Fig. 2. We performed micro-hardness scans across the surface of rail heads cut perpendicular to the direction of rail travel, making indentations at $3 \mathrm{~mm}$ intervals. We also extracted standard small tensile samples, with their tensile axes parallel to the direction of rail travel, from regions across the rail head surface consistent with the indentation measurements. We conducted these experiments on material from virgin rail and from heavily used, but un-cracked, rail. Table I shows the compositions of the steels used in this study.

Figure 3 shows the results of the micro-hardness (Vickers) scans. In the case of the virgin rail, the hardness variation across the rail head is less than $10 \%$, which is in the normal range of variation for such properties. There is some indication of a higher hardness in the surface region, perhaps a result of the fabrication process. The micro-hardness variation across the face of the heavily used rail is also within $10 \%$, except for a region at the top surface, particularly at the gage corner. As mentioned earlier, this is where shear forces from friction are greatest. Outside of this region, the Vickers hardness of the heavily-used rail is not very different from that of the virgin rail.

In Fig. 4, we show the results of tensile tests conducted on samples from the two kinds of rail material. The cluster of flow curves in the lower stress range were generated from tests on samples taken from both the heavily used rail, from regions away from the gage corner, and from all regions of the virgin rail. These clustered flow curves deviate from the mean (solid line) by less than $10 \%$. The single flow curve in the higher stress range shown in Fig. 4 was generated from a test on a sample taken from the near-surface region of the gage comer. This is the same region where the Vickers hardness was notably higher, as shown in Fig. 3.

Crack Propagation: The previous results suggest that severe cyclic deformation incurred in the heavily used rail during service produces sub-surface deformation debris, primarily at the gage corner. This is reflected in a substantially higher hardness in that region, and a very different flow behavior. The ability of the material in this region to harden further is limited and it is therefore less forgiving to further cyclic loading. Consequently, interfacial stresses at inclusions in the steel in this region cannot be easily mitigated by plastic flow. Cracks can nucleate at these interfaces, and they can propagate with continued service cycles. The location of the hardened region supports the idea [2] that the shear load from friction plays a significant role in the cracking process. Hence, reducing friction can mitigate the crack nucleation process and reduce the crack propagation rate, resulting 
in an extension of rail life.

The geometry of the sub-surface cracks of interest to us is such that they are subjected to mixed-mode cyclic loading (Mode I plus Mode II). Mode I tensile loading comes from the release of the normal load as a train passes, and Mode II loading is the result of shear forces from friction. Based on the work of Weertman [7], Tanaka [8] has shown that, for this mixed-mode case, the crack propagation rate can be expressed as,

$$
\frac{d a}{d \dot{N}} \equiv R \propto\left(K_{l}+8 K_{I I}\right)^{4}
$$

Assuming remote normal and shear loading, and that the shear load comes from friction, one can express $\mathrm{R}$ as a function of the friction coefficient:

$$
R \propto K_{I}^{4}(1+8 \mu)^{4}
$$

It is clear from this equation that if we can reduce the friction coefficient of untreated rail steel (defined as $\mu_{\mathrm{V}}$ ) via surface modification, we can anticipate a considerable reduction in crack propagation rate. We define the fractional change in propagation rate $f_{R}$ relative to the properties of untreated materials as

$$
f_{R} \equiv \frac{\left(R_{V}-R\right)}{R_{V}}=1-\left[\frac{(1+8 \mu)}{\left(1+8 \mu_{V}\right)}\right]^{4}
$$

We will use this equation later to calculate the reduction in cracking rate for measured reductions in friction coefficient achieved through laser glazing.

\section{Surface Modification Issues}

Railroad rails are made (essentially) of plain eutectoid (AISI 1080) steels, and begin service with a pearlitic microstructure. Pearlite is tough and ductile, but soft, particularly in relation to the heavy loads to which rails are subjected. This material is very susceptible to the kinds of surface deformation and sub-surface build-up of dislocation debris discussed earlier and to the sub-surface cracking associated with those phenomena. In addition, at the load levels sustained by rails, considerable energy is absorbed by plastic deformation and redistribution of material in the rail surface layers, which can be reflected in the friction forces experienced. An ideal surface layer that would mitigate these conditions, and the cracking that comes from them, is one that is substantially harder then the pearlitic substrate, but more elastically compliant. It is known that laser glazing, the rapid solidification $\left(10^{6}-10^{12} \mathrm{~K} / \mathrm{s}\right)$ of a thin melt layer produced by the passage of an energetic laser beam, can produce very fine non-equilibrium microstructures that are very hard [4]. It has also been 
acknowledged [5] that, because of the rapid solidification rates, laser glazing may produce amorphous films under certain conditions. If amorphous films were produced, they would exhibit a greater than $50 \%$ higher yield strength than the substrate, be $-30 \%$ more elastically compliant than the substrate, and, after yielding, would flow perfectly plastically without hardening [9], i.e. without the build-up of sub-surface dislocations. Amorphous films produced on steels by ion implantation have been demonstrated to reduce friction and wear [10] and prohibit the penetration of plastic flow into the substrate [11].

The strategy pursued in this research was to produce an amorphous glaze on a rail steel surface by the rapid solidification of a less than $100 \mu \mathrm{m}$ thin melt layer produced on the massive heat sink of the rail itself by passing an appropriately focused laser beam across its surface. The properties of this layer are expected to be conducive to achieving reduced friction and mitigated cracking. The high yield strength of the glaze material allows less energy to be dissipated in plastic flow during loading. The high compliance of amorphous metals allows the load to be distributed more uniformly to the substrate, limiting penetration of plasticity into the substrate. The nonhardening flow of the glaze reflects the fact that the amorphous structure is more open, allowing atomic rearrangements to accommodate localized shear without the build up of dislocations within the film. This will mitigate the occurrence of delamination processes in the film. It is expected that the rapid cooling rate afforded by the heat sink will result in the formation of a hard martensitic heataffected-zone beneath the glaze, which will serve to match the high strength of the glazed layer and the compliance of the pearlitic substrate. Finally, the strong, tough, ductile pearlitic steel microstructure remains beneath the hard surface film produced by the glazing process. Therefore, the glazing process results in intimately bonded interfaces between the modified surface layers and the substrate, and provides a microstructurally blended transition between the layers.

\section{Laser Treatments}

Processing: Laser glazing treatments were performed at Argonne National Laboratory's Laser Applications Laboratory. The facility includes a $6 \mathrm{~kW}$ Rofin-Sinar $\mathrm{RS} 6000 \mathrm{CO}_{2}$ laser and a $1.6 \mathrm{~kW}$ Electrolux Nd:YAG laser. The treatments reported here were all obtained using the $\mathrm{Nd}$ :YAG laser system. This is a durable solid-state laser with a wave length $(1.06 \mu \mathrm{m})$ that allows glazing (rapid melting through thermal coupling with the rail steel) without the need for application of an absorptive coating. It also allows the beam to be delivered through flexible fiber-optic cable, which is a useful feature for remote in-track applications of interest to the railroad industry. The Laser Applications Laboratory possesses the necessary beam diagnostics and characterization capabilities that allow experimenters to monitor and control the beam intensity profile and shape. Figure 5 shows a typical depiction of beam profile that can be generated.

Table II shows the variety of beam conditions for the laser treatments reported in this paper. Generally, about $1 \mathrm{~kW}$ of power was delivered to the samples used in this study, as the beam moves along their surfaces. Two laser beam shapes were obtained with different sets of lens configurations: an elliptical beam cross-section with a $5 \mathrm{~mm}$ major axis oriented perpendicular to the direction of travel along the sample. and a circular beam cross-section with a $2 \mathrm{~mm}$ diameter. The beams were 
moved along the samples at speeds of either 1 or $2 \mathrm{~cm} / \mathrm{s}$, and glazing treatments involved passes of 2 - 5 inches in length. Some treatments consisted of only a single pass $(5 \mathrm{~mm}$ or $2 \mathrm{~mm}$ wide, depending on the beam cross-section) along the sample, while others were multiple pass treatments, either overlapping by a $1 \mathrm{~mm}$ offset, or adjacent to one another, separated by $1 \mathrm{~mm}$. The laser passes were conducted with a nitrogen cover gas directed at the sample. As indicated in Table II, three kinds of samples were used in this study. Preliminary laser glaze treatments were performed on the top (loading) surface of a small section of actual rail head (unused) provided by the Association of American Railroads (AAR). Based on the results of microstructure and hardness (Vickers) studies conducted on these preliminary samples, a series of laser glaze operations were performed on flat plates of AISI 1080 steel similar to rail steels (see Table I for composition). Samples for friction measurements were extracted from these samples. Samples for microstructure, hardness and X-ray studies were also extracted from these AISI 1080 steel samples. Finally, laser glaze treatments were applied to portions of the top surface of an intact six-foot length of rail, suitable for inclusion in the AAR Research and Test Department's Cyclic Rolling-Sliding Wear Machine, for in situ friction measurements.

Figure 6 shows examples of two kinds of laser tracks produced on an AISI 1080 steel plate. The view is looking down on the treated surface. As can be seen from the markings on the plate outside the laser tracks, the treatments were applied to the as-machined surface. Figure 6a shows a multiple (ten) pass treatment, with each succeeding pass overlapping the previous one by $1 \mathrm{~mm}$, and reversing direction on each pass. In this case the circular beam was moved along the sample at $2 \mathrm{~cm} / \mathrm{s}$. Figure $6 \mathrm{~b}$ shows a single-pass treatment, where the elliptical beam was moved along the sample at $1 \mathrm{~cm} / \mathrm{s}$. The "chevron" markings visible on some of the tracks are remnants of the melting process as the beam moved along the sample exposed to the cover gas. The dull finish on the single pass track is a thin oxide layer, easily removable with a soft cloth.

Microstructure and Hardness: Figure 7 shows optical micrographs of a cross section of the laser glazed region from preliminary treatments performed on the surface of an actual rail head. The black regions in the three micrographs are the phenolic mounting material. Figure 7 a shows three regions: the thin glazed $(G)$ layer formed at the surface; the heat-affected zone $(H)$, consisting of a fine martensite structure; and the pearlitic substrate $(S)$. Fig. 7b shows the intimately bonded interface between the heat-affected zone and the substrate, with Vickers indentations at the same load in each region. The microhardness of the substrate is $\mathrm{H}_{\mathrm{V}} 300$, while that of the heat-affected zone is $\mathrm{H}_{\mathrm{V}} 840$. The glazed layer has a hardness of $\mathrm{H}_{\mathrm{V}} 800$ for this sample. Figure 7c shows this cross section unetched, revealing the high integrity of the interface between the layers, and indicating that the high hardness of both the heat-affected zone and the glazed layer resists the scratching produced by the diamond palish process evident in the soft substrate. As discussed earlier, it is this near-surface layered microstructure, which we believe will reduce friction and mitigate fracture. Figure 8 shows some of the microstructural features of samples of the AISI 1080 steel plates that were laser treated. In Fig. 8a. the pearlitic microstructure, typical of rail-steel and of the substrate before glazing, is shown. It has a microhardness of $\mathrm{H}_{\mathrm{v}} 250-\mathrm{H}_{\mathrm{v}} 300$. Fig. $8 \mathrm{~b}$ shows the glazed region (white) and the heat-affect zone, with an untempered martensite structure. just beneath the glaze, produced by a single pass treatment with an elliptically shaped laser beam moving at $1 \mathrm{~cm} / \mathrm{s}$. The 
hardness of the glazed layer is $\mathrm{H}_{\mathrm{V}} 689$, while that of the untempered martensite heat-affected zone is $\mathrm{H}_{\mathrm{v}} 1072$. Figure $8 \mathrm{c}$ shows the near-surface microstructural features of an AISI 1080 steel sample subjected to a multiple pass process. This process involves overlapping tracks produced by an elliptically shaped beam moving along the sample at $1 \mathrm{~cm} / \mathrm{s}$ in one direction, shifting at the end of travel by $1 \mathrm{~mm}$, reversing direction and overlapping the previous track, and repeating this process as often as required to produce a treated area of a desired width. In this case, the heat from each succeeding pass tempers the martensite in the heat-affected zone produced by the previous pass. The glazed region has a hardness of $\mathrm{H}_{\mathrm{V}} 655$, slightly softer than that for the single pass case, but substantially harder than the substrate, while the tempered martensite $\left(\mathrm{H}_{V} 470\right)$ is considerably softer than the untempered martensite heat-affected zone produced by the single pass process, but still harder than the substrate. The microstructure of an overlapping multiple-pass treatment is shown in Fig. 9.

\section{Friction Measurements}

Measurements on AISI 1080 Steel Samples: Standard ASTM G77-93 friction-test samples were extracted from the laser-treated AISI 1080 steel test plates. Dry, static "block-on-ring" friction tests (ASTM G77-93) were performed on these samples by Falex Corporation, who were instrumental in devising this test. In these tests, the load is applied to the sample via an S-10 steel (Rockwell $\mathrm{C} 58-63, \sim \mathrm{H}_{\mathrm{v}} 730$ ) ring, which nominally makes a line contact with the treated surface. Normal loads ranging from $100 \mathrm{lbs}$ to $900 \mathrm{lbs}$, in $100 \mathrm{lb}$ increments, are applied, and the lateral force required to initiate rotation of the ring $(0.013 \mathrm{rpm})$ was measured in each case. The static friction coefficient was obtained therefrom. Figure 10 shows the results of friction coefficient determinations as a function of load, comparing the behavior of an untreated sample with the behaviors of samples subjected to a number of different single and multiple pass treatments. The maximum load for these experiments, i.e. $900 \mathrm{lbs}$, corresponds to normal stress levels that are close to prototypic stresses experienced by railroad rails in service. From the results shown in Fig. 10, it appears that laser glazing can reduce the friction coefficient by $25 \%$ at these stress levels.

We have postulated that reductions in friction coefficient could be achieved as a result of the creation of non-equilibrium phases, perhaps amorphous films, produced on the surface by the glazing process. We have performed X-ray diffraction experiments on the treated friction samples just described, in order to obtain information regarding the phases extant on their surfaces. Figures 11 - 14 show the results of X-ray scans performed on some of the successfully treated AISI 1080 steel samples, accompanied by the friction results obtained for these samples. Figure 11 shows the $X$-ray data that we obtained for the untreated surface of an AISI 1080 steel plate. The readily identifiable peaks observed are those of $\alpha$-ferrite. Figure 12 shows the results of a scan performed on a sample that received a single pass laser glaze treatment with a beam of circular cross section. In addition to some diffuse scattering effects and the $\alpha$-ferrite peaks, a peak consistent with the presence of martensite is also indicated (M). The reduced friction coefficient resulting from this treatment is also shown in the figure in comparison with that of the untreated sample. The X-ray scan for a sample given a multiple overlapping pass treatment with a circular beam is shown in Fig. 13 along with that of the untreated sample. In addition to the $\alpha$-ferrite peaks (not labeled) and 
diffuse scattering effects, a peak consistent with the presence of martensite $(M)$ and peaks consistent with the presence of cementite $(\mathrm{C})$ and $\mathrm{Fe}_{2} \mathrm{~N}(\mathrm{~N})$ are labeled. We were unable to identify a number of phases in this sample. Figure 14 shows the scan for a sample given a single pass treatment with an elliptically shaped beam along with the scan of the untreated sample. The treated sample scan contains peaks consistent with $\alpha$-ferrite, martensite and cementite. Other peaks in the scan could not be identified, and the scan contained some diffuse scattering effects. Because of the rapid solidification and rapid cooling after solidification associated with the laser glazing process, it is possible that a number of the phases formed are not equilibrium phases. However, except for some diffuse scattering regions in the scans, these results provide no conclusive evidence of the formation of an amorphous film on the laser treated samples. Nonetheless, all of the samples shown exhibit a reduction in the coefficient of friction of the order of $25 \%$ at loads corresponding to prototypic rail service loads.

Measurements on a Section of Railroad Rail: Encouraged by the friction results just described for samples extracted from AISI 1080 steel test plates, we laser glazed two sections of a six-foot length of railroad rail provided by the AAR for further testing. This length of rail is suitable for insertion in the AAR Transportation Technology Center's Cyclic Rolling-Sliding Wear Machine in Pueblo, CO. The glazed sections (Fig. 15) were centered on the top of the rail. They are each 4 inches long, in the rail travel direction, about 0.75 inches wide, and are separated by 4 inches of untreated surface. One of the glazed regions involves a multiple pass treatment with overlapping laser tracks. In this case, a beam with a $2 \mathrm{~mm}$ diameter circular cross section, moving at $2 \mathrm{~cm} / \mathrm{s}$, is used to produce a single laser track that is four inches long. Then the beam is offset by a millimeter and its travel direction reversed, so that it produces a neighboring 4-inch long laser track that partially overlaps the first. This is repeated until ( 20 passes in total) an overlapping glazed region of 4 " $x 0.75^{\prime \prime}$ is produced. The other glazed region is also a multiple pass treatment, but the adjacent tracks do not overlap. In this case, an elliptical (cross-section) beam with a $5 \mathrm{~mm}$ major axis perpendicular to the direction of travel, moving at $1 \mathrm{~cm} / \mathrm{sec}$, was used to produce each separate laser track. The tracks were separated by $5 \mathrm{~mm}$, so four passes produce the desired 4 " $\times 0.75^{\text {" glazed }}$ region. As a reminder, we should note that a goal of this work is to reduce the friction at the gage comer of the rail, not the top. However, we treated the top surface of this 6-foot test rail in order to facilitate friction measurements.

The Cyclic Rolling-Sliding Wear Machine is capable of applying a range of normai loads and controlled tangential forces to the rail via actual wheel-rail contact through back-and-forth cycles, while monitoring the magnitude of these forces. Therefore, the machine capabilities allow the determination of the friction coefficient as a function of normal load at glazed and untreated positions along the rail. After insertion of the six-foot test rail piece, experiments were performed in accordance with the following procedure. The loading wheel was loaded to 39,000 lbs (nearprototypic service load), and 50 cycles (back and forth) of pure rolling were applied to the rail as a run-in procedure. After this procedure, the laser-modified surfaces were examined visually, and found to be intact. Preliminary friction experiments, at normal loads ranging from 5,000 to 40,000 $\mathrm{lbs}$, were then conducted on the two laser-treated regions and on the untreated region between them in order to define test the procedure. In these experiments, a tangential load was applied to the wheel 
to produce a turning moment. During these tests, it was found that two distinct measurements were appropriate for each condition and location: the value of the friction coefficient associated with the tangential force required to just start wheel rotation $\left(\mu_{\mathrm{s}}\right)$, and the value of the friction coefficient associated with the tangential force required to have the wheel rotate freely $\left(\mu_{\mathrm{f}}\right)$. Reductions in friction coefficient were observed for the laser-treated regions, but, unfortunately, these preliminary measurements were not sufficiently precise to report here.

It was intensely important to the AAR that the durability of the laser treatments be tested. Therefore, after the preliminary friction experiments were conducted and before more precise friction measurements were made, the rail surface was subjected to 20,000 back-and-forth cycles in pure rolling at $39,000 \mathrm{lbs}$ of normal load. The treated surfaces were visually inspected and examined with dye penetrant, and found to be completely intact, with no evidence of cracking. Friction coefficient measurements were made, as described previously, at normal loads of 5,000,10,000,20,000,30,000 and $40,000 \mathrm{lbs}$. After these measurements, the rail surface was subjected to 10,000 additional backand-forth rolling-sliding cycles at $39,000 \mathrm{lbs}$ normal load combined with $8,000 \mathrm{lbs}$ tangential force. Subsequent visual inspection showed no evidence of cracking in the laser-treated areas. Figures 16 and 17 show the results of the friction coefficient measurements made, after the 20,000 rolling cycles treatment, on the overlapped laser-treated area (Fig. 16) and on the adjacent-pass laser-treated area (Fig. 17) in comparison with measurements made on the untreated area. The results show that, at prototypic loads $(40,000 \mathrm{lbs})$ the friction coefficient associated with the free rotation of the wheel $\left(\mu_{f}\right)$ was reduced by about $40 \%$ relative to the untreated surface. The breakaway friction coefficient $\left(\mu_{s}\right)$ is reduced by from $20 \%$ to $50 \%$ at prototypic loads, which is as good or better than the results obtained in the laboratory on laser-treated AISI 1080 steel.

Crack Propagation Rate Reductions: The overall goal of this research is to mitigate subsurface cracking in railroad rails by reducing the shear forces imposed on the rail from friction. We postulated that this could be achieved via laser surface modification (glazing) to reduce the friction coefficient of rail steel. We have just shown substantial reductions in the friction coefficient produced by a durable laser surface modification. We showed earlier that crack propagation rate reductions can be expressed in terms of friction coefficient by the equation:

$$
f_{R} \equiv \frac{\left(R_{V}-R\right)}{R_{V}}=1-\left[\frac{(1+8 \mu)}{\left(1+8 \mu_{V}\right)}\right]^{4}
$$

Table III shows the calculated reductions in crack propagation rate for the reductions in friction coefficient achieved via laser treatments performed in this study, and observed both in laboratory static friction experiments and in experiments more prototypic of rail service. It can be seen that, according to this equation, cracking rates can be significantly reduced, which can be directly related to possible substantial extensions in rail life. 


\section{Summary}

Shear loads from rail-wheel friction contribute significantly to sub-surface cracking in railroad rails. In this paper, we have explored and demonstrated the feasibility of mitigating this problem by reducing friction through laser surface modification. This process allows one to target locations on the rail where the problem exists, and can be applied to rails in service, during re-work programs and, perhaps, during fabrication. We have shown that commercially available laser systems can be used to produce appropriately "glazed", i.e. rapidly melted and rapidly solidified, railsteel surfaces. The Nd:YAG laser that was used requires no pretreatment absorbtive coating to couple with and melt the rail surface. The laser beam was delivered to the work area via fiber-optic cable, which is convenient for in-service applications. The laser-modified surfaces possessed hard non-equilibrium microstructures that were intimately bonded to the substrate, and the modified region itself, from the surface glaze to the heat-affected-zone to the substrate, involved well-blended microstructure and properties. Both single-pass and multiple-pass (overlapped and adjacent laser tracks) produced substantial reductions in the friction coefficient of AISI 1080 steel test plates and actual rail surfaces. The laser-glaze treatment induced friction coefficient reductions, measured at prototypic'rail service loads, by as much as $40 \%$, corresponding to reductions in calculated subsurface crack propagation rate as high as $79 \%$.

\section{Acknowledgment}

This work was supported by the Association of American Railroads under WFO Contract 85 G23 and by the US DOE Technology Support Programs under Contract W-31-109-ENG-38. The authors gratefully acknowledge Mr. George F. Vander Voort of Buehler Ltd. for his help with metallography and the Mr. Steven W. Ruddy of the Falex Corporation for performing block-on-ring friction experiments.

\section{References}

1. Association of American Railroads, private communication, 1996.

2. E. Gervais and H.J. McQueen, J. Iron and Steel Inst., March, 1972, 189.

3. R.J. DiMelfi, Scripta Met. 21 (1987) 421.

4. P.R. Strutt, H. Nowotny, M. Tuli and B.H. Kear, Mat. Sci. Eng. $\mathbf{3 6}$ (1978) 217.

5. D.W. Hetzner, Fifth International Symposium on Bearing Steels: Into the $21^{\text {st }}$ Century, ASTM STP 1327, J.J. Hoo Ed., American Society for Testing and Materials, 1997.

6. J. Singh, JOM 44 \#9 (1992) 8.

7. J. Weertman, Int. J.Fracture, $\underline{\mathbf{2}}$ (1966) 460.

8. K. Tanaka, Int. J. Fracture, $\underline{6}$ (1974) 493.

9. J.J. Gilman, J. Appl. Phys. 46 (1975) 1625.

10. D.M. Follstaedt, J.A. Knapp and L.E. Pope, Materials Research Society Proceedings, Vol. 140, 1989, p.1017.

11. R.J. DiMelfi, J. Mater. Eng. 12 (1990) 257. 
Table I. Compositions of Rail Steels and 1080 Steel Plates

\begin{tabular}{ccccccccccccc} 
Sample & $\mathrm{Si}$ & $\mathrm{P}$ & $\mathrm{Cr}$ & $\mathrm{Al}$ & $\mathrm{Mn}$ & $\mathrm{S}$ & $\mathrm{Mo}$ & $\mathrm{N}$ & $\mathrm{C}$ & $\mathrm{Ni}$ & $\mathrm{Cu}$ & $\mathrm{O}$ \\
\hline \hline $\begin{array}{c}\text { Virgin } \\
\text { Rail }\end{array}$ & 0.21 & 0.012 & 0.22 & $<0.01$ & 0.98 & 0.026 & 0.01 & .0085 & 0.80 & 0.08 & 0.22 & .0043 \\
\hline $\begin{array}{c}\text { Used } \\
\text { Rail }\end{array}$ & 0.18 & 0.022 & 0.02 & $<0.01$ & 0.82 & 0.008 & 0.01 & .0028 & 0.75 & 0.05 & 0.04 & .0065 \\
\hline $\begin{array}{c}\text { AISI } \\
1080\end{array}$ & 0.19 & 0.01 & - & - & 0.73 & - & - & - & 0.72 & - & - & - \\
\hline
\end{tabular}


Table II. Laser Treatments*

\begin{tabular}{|c|c|c|c|}
\hline & $\begin{array}{l}\text { Preliminary Runs } \\
\text { (Rail Head) }\end{array}$ & $\begin{array}{c}1080 \text { Steel Plates for Friction } \\
\text { Tests }\end{array}$ & $\begin{array}{l}\text { Laser Treated } \\
\text { 6-foot Rail Section }\end{array}$ \\
\hline $\begin{array}{l}\text { Delivered } \\
\text { Power }\end{array}$ & $\sim 1084 \mathrm{~W}$ & $\begin{array}{l}944 \mathrm{~W}(\mathrm{c})^{\dagger} \\
1084 \mathrm{~W}(\mathrm{e})^{\ddagger}\end{array}$ & $\begin{array}{l}944 W(c) \\
1084 W(e)\end{array}$ \\
\hline Beam & èlliptical (5mm) & $\begin{array}{l}\text { circular }(2 \mathrm{~mm}) \\
\text { elliptical }(5 \mathrm{~mm})\end{array}$ & $\begin{array}{l}\text { circular }(2 \mathrm{~mm}) \\
\text { elliptical }(5 \mathrm{~mm})\end{array}$ \\
\hline Speed & $1 \mathrm{~cm} / \mathrm{s}$ & $\begin{array}{l}2 \mathrm{~cm} / \mathrm{s}(\mathrm{c}) \\
1 \mathrm{~cm} / \mathrm{s}(\mathrm{e})\end{array}$ & $\begin{array}{l}2 \mathrm{~cm} / \mathrm{s}(\mathrm{c}) \\
1 \mathrm{~cm} / \mathrm{s}(\mathrm{e})\end{array}$ \\
\hline Overlap & NO (Single Pass) & $\begin{array}{c}\mathrm{NO}(\mathrm{c} \text { and } \mathrm{e}) \\
\text { and } \\
\text { Yes, } 1 \mathrm{~mm} \text { raster (c and } \mathrm{e})\end{array}$ & $\begin{array}{c}\text { NO (e, Parallel Passes) } \\
\text { and } \\
\text { Yes, 1mm raster (c) }\end{array}$ \\
\hline
\end{tabular}

* Laser Passes Conducted with $\mathrm{N}_{2}$ Cover Gas

${ }^{\dagger} \mathrm{c}$ represents circular cross section

$\ddagger$ e represents elliptical cross section 
Table III. Calculated Crack Propagation Rate Reductions, $\mathbf{f}_{\mathbf{R}}$

\begin{tabular}{c|ccccc}
\hline & AISI 1080 & AAR Rail & AAR Rail & AAR Rail & AAR Rail \\
& Overlap $^{\mathrm{a}}$ & Separate & Separate & Overlap & Overlap \\
& Static $^{\mathrm{b}}$ & Static & Dynamic & Static & Dynamic \\
& $\mathrm{f}_{\mu} \cong 25 \%$ & $\mathrm{f}_{\mu} \cong 20 \%$ & $\mathrm{f}_{\mu} \cong 40 \%$ & $\mathrm{f}_{\mu} \cong 50 \%$ & $\mathrm{f}_{\mu} \cong 40 \%$ \\
& $\mu_{\mathrm{V}} \cong 0.4$ & $\mu_{\mathrm{V}} \cong 0.3$ & $\mu_{\mathrm{v}} \cong 0.5$ & $\mu_{\mathrm{V}} \cong 0.3$ & $\mu_{\mathrm{v}} \cong 0.5$ \\
\hline \hline $\begin{array}{c}\text { Fractional } \\
\text { Reduction in } \\
\mathrm{R}, \mathrm{f}_{\mathrm{R}}\end{array}$ & $\sim 57 \%$ & $\sim 46 \%$ & $\sim 79 \%$ & $\sim 82 \%$ & $\sim 79 \%$ \\
& & & & & \\
\hline
\end{tabular}

a. The terms overlap and separate refer to either overlapping or separated multiple-pass laser treatments, respectively.

b. The terms static or dynamic refer to either breakaway friction coefficient measurement or continuous friction measurement, respectively. 
Figures

Figure 1. A schematic representation of a rail head, showing a crack propagating along the rail travel direction in the sub-surface region beneath the gage corner.

Figure 2. Schematic drawings of rail heads, showing (a) a representation of the $3 \mathrm{~mm}$ grid on which micro-hardness scans were performed, and (b) a representation of the end sections (viewed edge-on) of tensile samples whose tensile axes lie parallel to the rail travel direction, i.e. normal to the page. Hardness and tensile tests were performed on samples extracted from both virgin and heavily-used rail.

Figure 3 Schematics of rail heads showing the results of hardness (Vickers, $300 \mathrm{~g}$ ) scans performed on the rail head cross sections of (a) virgin rail and (b) heavily-used rail. The sub-surface region of the gage comer of the heavily used rail, where significant deformation occurred during service, is substantially harder than either the virgin rail or the remainder of the heavily used rail.

Figure 4. The tensile behavior of rail steel samples taken from both virgin and heavily used rail. The cluster of curves in the low stress region show the behavior of all rail samples and heavily used rail samples taken from regions away from the gage corner. The outlying curve in the high stress region is the behavior of a sample taken from the sub-surface region beneath the gage corner of the heavily-used rail.

Figure 5. Isometric depiction of a laser beam intensity profile.

Figure 6. Photographs of laser-glazed regions produced on AISI 1080 steel plates. Figure 6a, left, is of a multiple overlapping-pass treatment produced by a circular beam moving at $2 \mathrm{~cm} / \mathrm{s}$. Figure $6 \mathrm{~b}$ is of a single pass treatment produced by an elliptical beam moving at $1 \mathrm{~cm} / \mathrm{s}$. The photographs were taken looking down on the treated surfaces.

Figure 7. Optical micrographs of the cross section of the laser treated region from preliminary treatments performed on the surface of a rail head. Figures (a) and (b) show the samples etched with Vilella's etchant.

Figure 8. Optical micrographs of the cross sections of laser treated AISI 1080 steel plates. Figure (a) is the untreated substrate region, (b) shows the microstructure of the glazed region from a multiple-pass overlapping glazing treatment, and (c) shows the microstructure of a single-pass treatment. Samples are etched with Nital.

Figure 9. A multiple-pass overlapping Nd:YAG laser treatment ( $944 \mathrm{~W}$ delivered power) using an elliptical ( $5 \mathrm{~mm}$ diameter) beam moving at $1 \mathrm{~cm} / \mathrm{s}$. The next-to-last pass and the last pass are shown. Heat from the last pass tempers the martensite in the next-to-last pass: 
Figure 10. Measurements of the friction coefficient for laser-treated AISI 1080 steel samples, shown as a function of normal load in comparison with results typical of untreated control samples. The measurements were obtained using standard (ASTM G77-93) block-on-ring friction tests.

Figure 11. The results of an X-ray scan taken of the untreated surface of an AISI 1080 steel plate.

Figure 12. The results of an X-ray scan obtained from an AISI 1080 steel sample that received a single pass laser treatment with a circular beam $(2 \mathrm{~cm} / \mathrm{s})$. In addition to the $\alpha$ ferrite peaks also seen in the untreated sample, there are some diffuse scattering effects and the indication of a peak consistent with the presence of martensite (M).

Figure 13. The X-ray scan from a sample that received a multiple overlapping-pass laser treatment with a circular beam $(2 \mathrm{~cm} / \mathrm{s})$ shown along with the results of the scan from the untreated sample (Fig. 11). The $\alpha$-ferrite peaks are still apparent along with peaks consistent with the presence of martensite, cementite $(C)$, and $\mathrm{Fe}_{2} \mathrm{~N}(\mathrm{~N})$, as well as some diffuse scattering effects. A number of peaks could not be identified.

Figure 14. The results of an X-ray scan of a sample that received a single pass laser treatment with an elliptical beam $(1 \mathrm{~cm} / \mathrm{s})$, shown with scan from the untreated sample. Peaks consistent with $\alpha$-ferrite, cementite (C) and martensite (M). A number of peaks could not be identified.

Figure 15. A photograph of a section of unused railroad rail that received two four-inch long laser glaze treatments on its top surface: a multiple overlapping pass treatment done with a circular beam (left), and a multiple pass treatment made up of single adjacent passes done with an elliptical beam (right).

Figure 16. The results of friction measurements made at the AAR's Cyclic Rolling-sliding Wear Machine on a rail surface given a multiple overlapping pass treatment with a circular beam $(2 \mathrm{~cm} / \mathrm{s})$. Measurements of breakaway friction (left, $\mu_{s}$ ) and freely rotating friction (right, $\mu_{f}$ ) are shown in comparison with the results for untreated surfaces of the rail.

Figure 17. The results of friction measurements made at the AAR's Cyclic Rolling-sliding Wear Machine on a rail surface given a multiple adjacent pass treatment with an elliptical beam $(1 \mathrm{~cm} / \mathrm{s})$. Measurements of breakaway friction (left, $\mu_{s}$ ) and freely rotating friction (right, $\mu_{i}$ ) are shown in comparison with the results for untreated surfaces of the rail. 


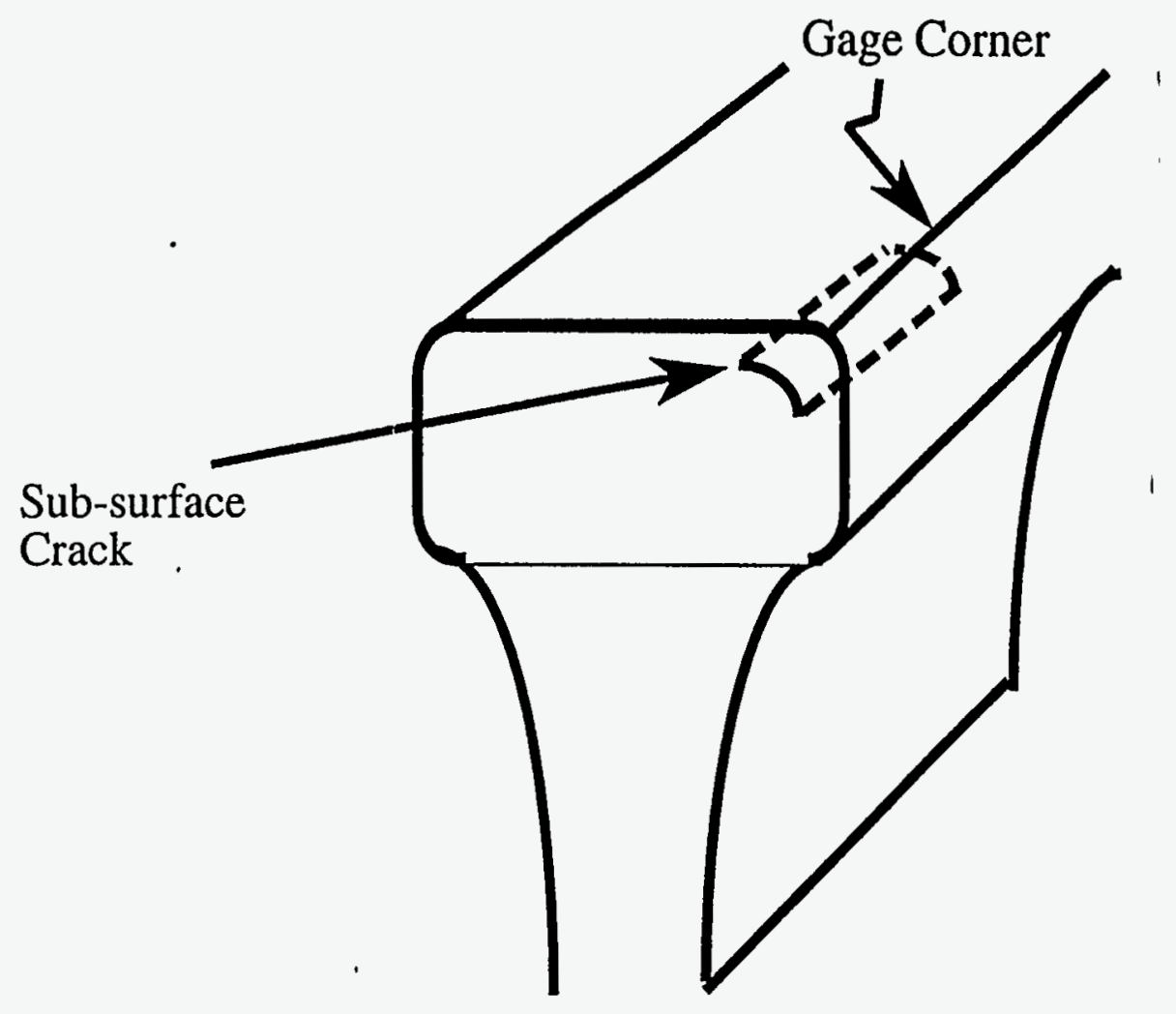

Figure 1. A schematic representation of a rail head, showing a crack propagating along the rail travel direction in the sub-surface region beneath the gage corner. 

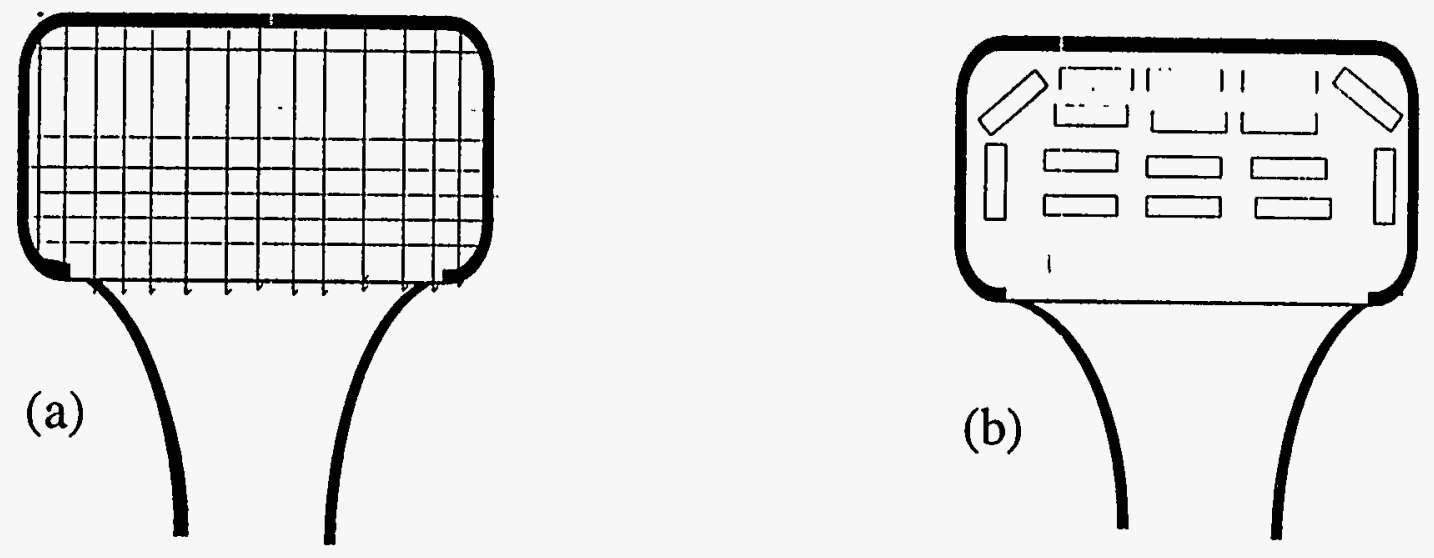

Figure 2. Schematic drawings of rail heads, showing (a) a representation of the $3 \mathrm{~mm}$ grid on which micro-hardness scans were performed, and (b) a representation of the end sections (viewed edge-on) of tensile samples whose tensile axes lie parallel to the rail travel direction, i.e. normal to the page. Hardness and tensile tests were performed on samples extracted from both virgin and heavily-used rail. 

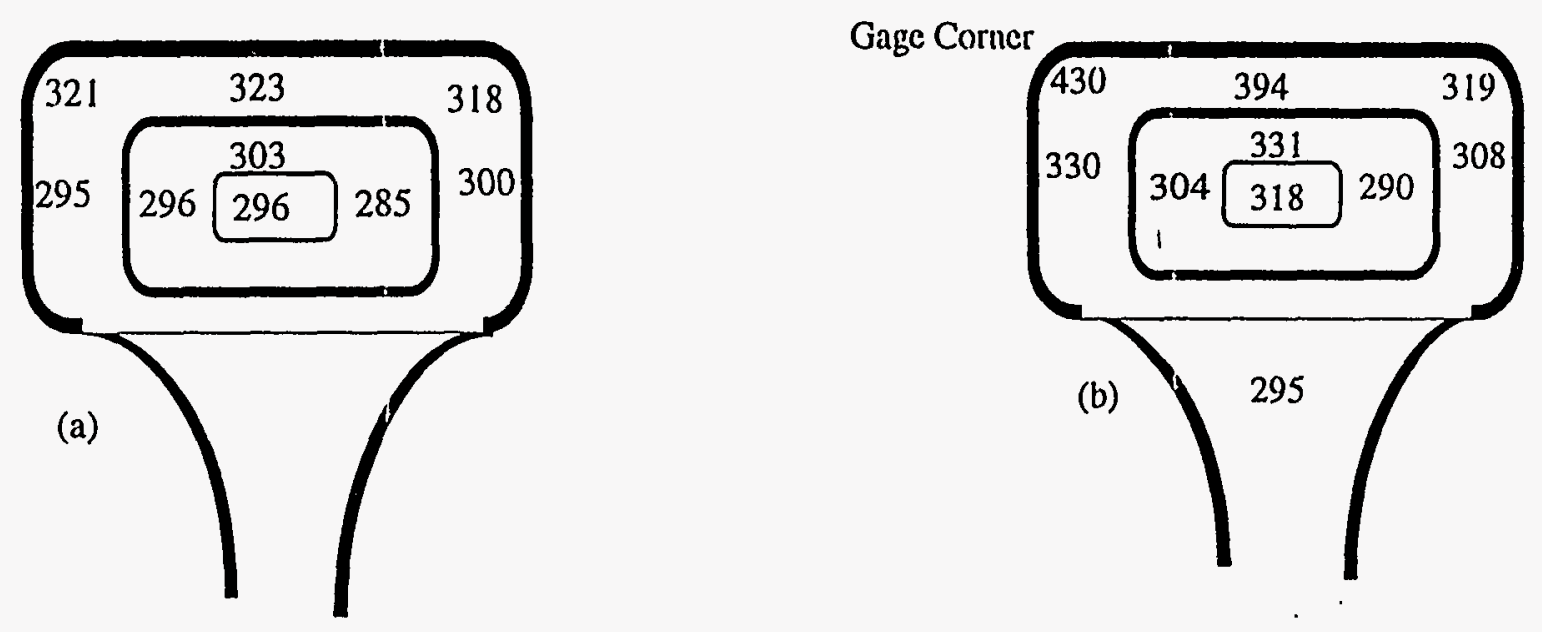

Figure 3. Schematics of rail heads showing the results of hardness (Vickers, $300 \mathrm{~g}$ ) scans performed on the rail head cross sections of (a) virgin rail and (b) heavily-used rail. The sub-surface region of the gage corner of the heavily used rail, where significant deformation occurred during service, is substantially harder than either the virgin rail or the remainder of the heavily used rail. 


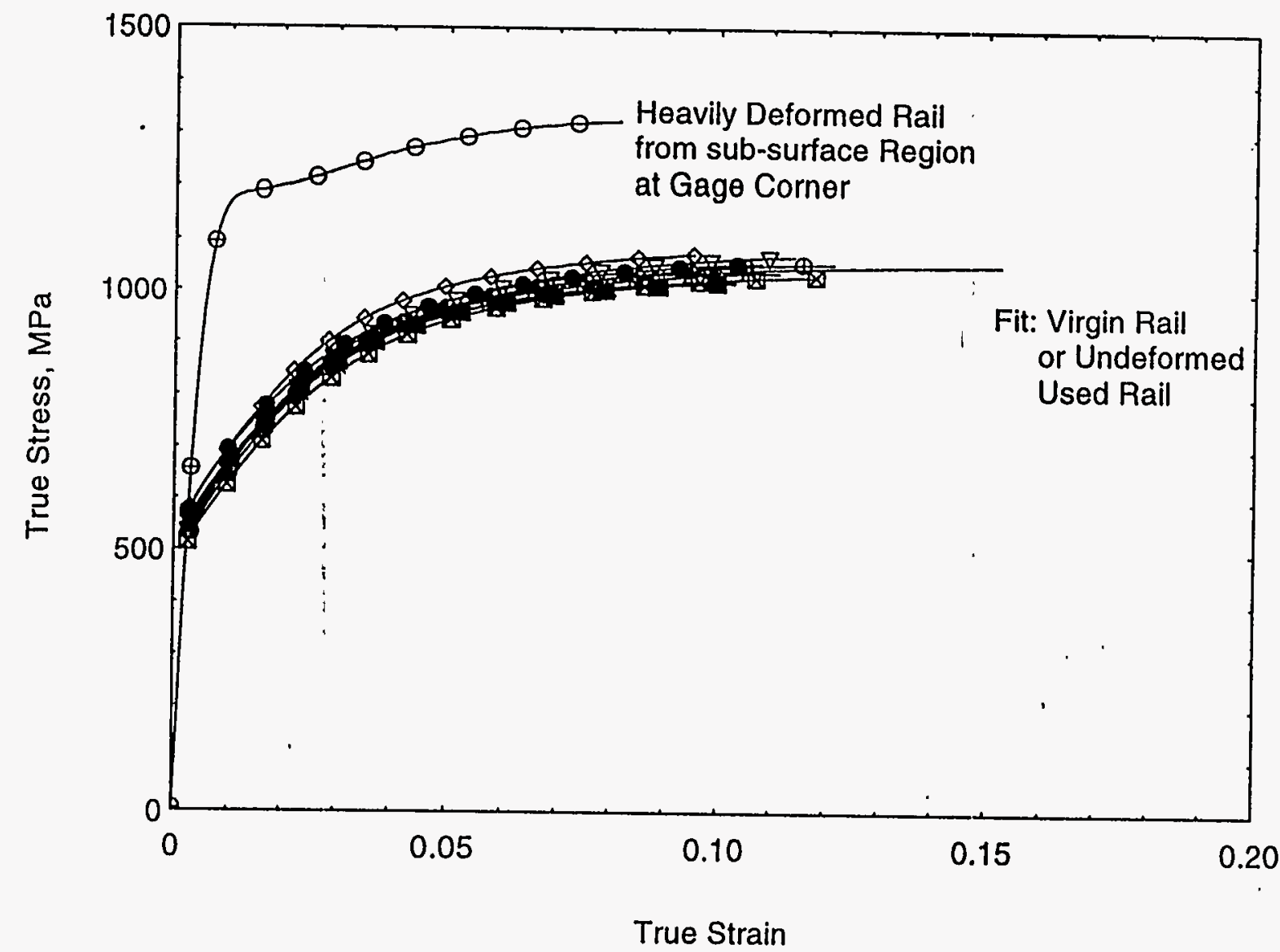

Figure 4. The tensile behavior of rail steel samples taken from both virgin and heavily used rail. The cluster of curves in the low stress region. show the behavior of all virgin rail samples and heavily-used rail samples taken from regions away from the gage corner. The outlying curve in the high-stress region is the behavior of a sample taken from the sub-surface region beneath the gage corner of the heavily-used rail. 


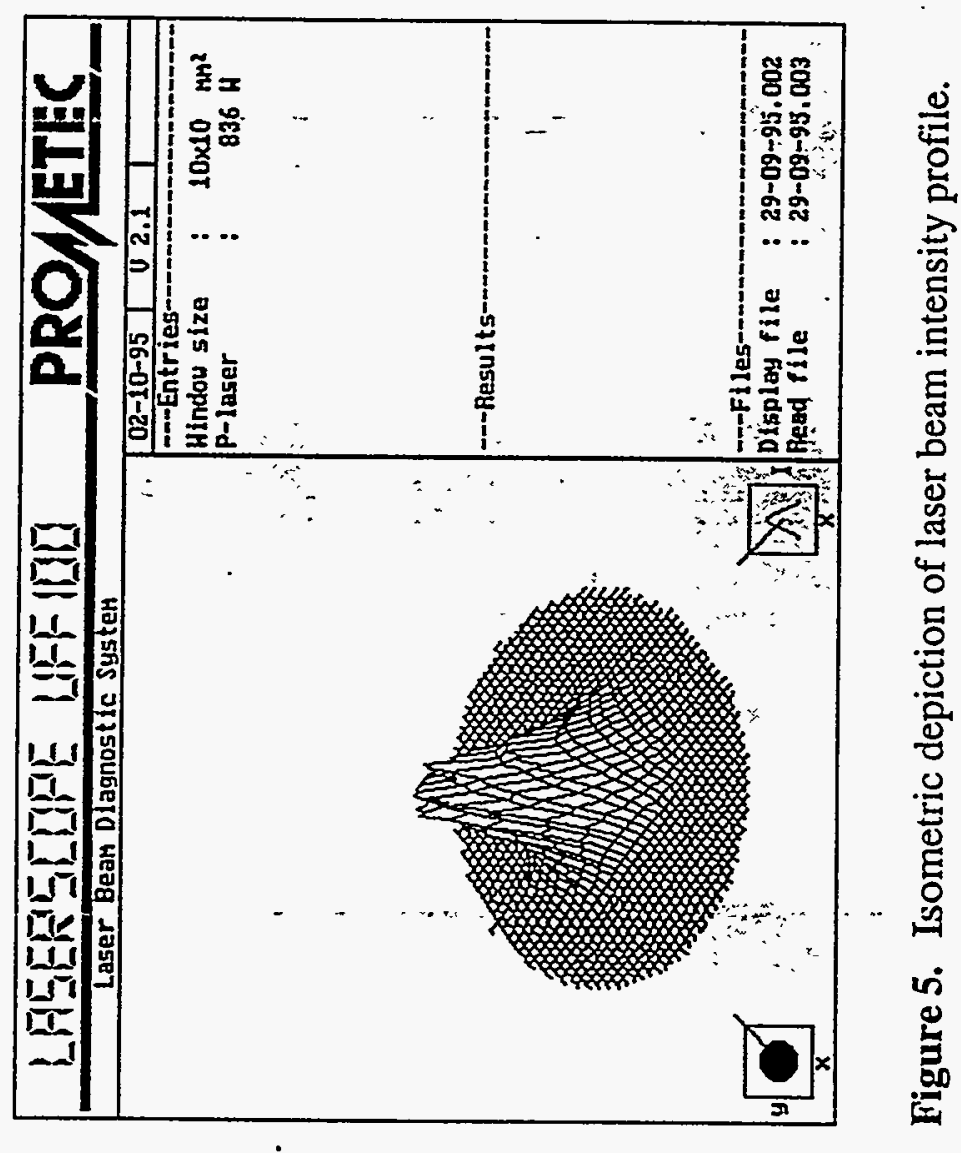


(a)

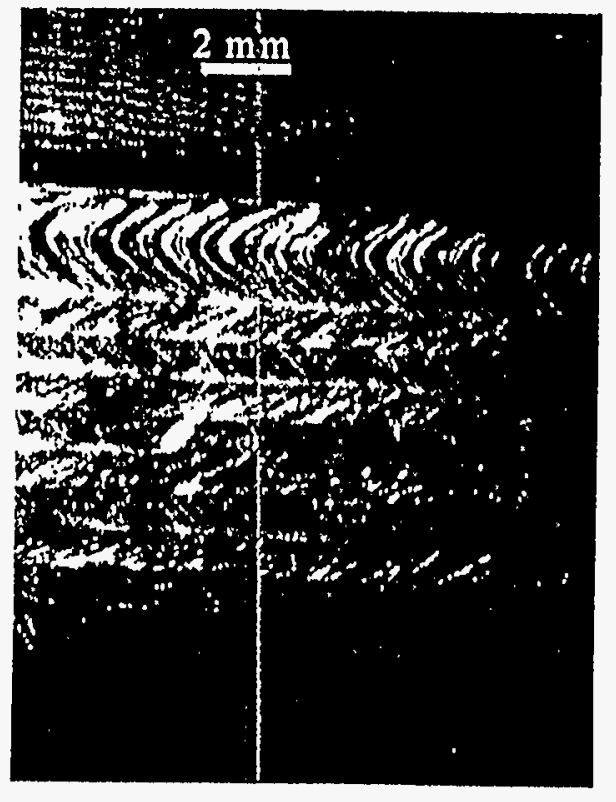

(b)

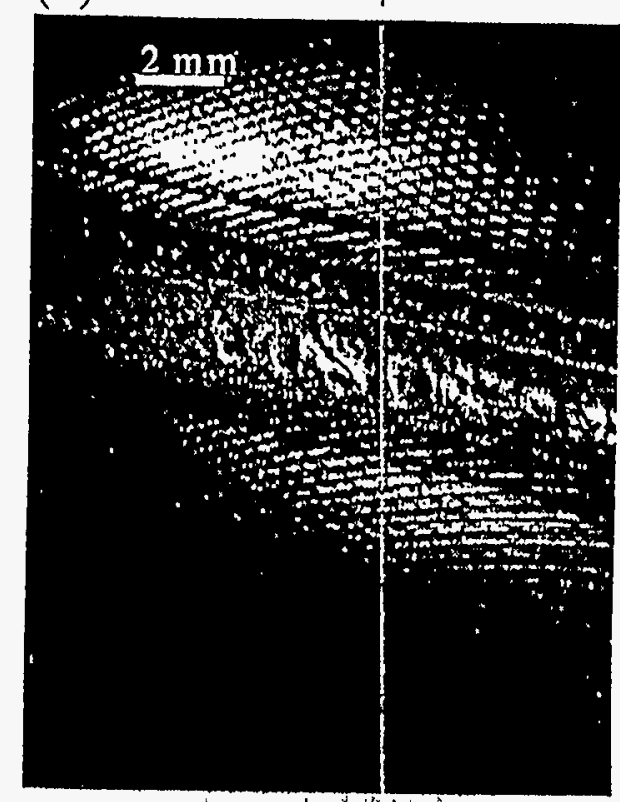

Figure 6. Photographs of laser-glazed regions produced on AISI 1080 steel plates. Figure $6 \mathrm{a}$, left, is of a multiple overlapping-pass treatment produced by a circular beam moving at $2 \mathrm{~cm} / \mathrm{s}$. Figure $6 \mathrm{~b}$ is of a single pass treatment produced by an elliptical beam moving at $1 \mathrm{~cm} / \mathrm{s}$. The photographs were taken looking down on the treated surfaces. 
(a)

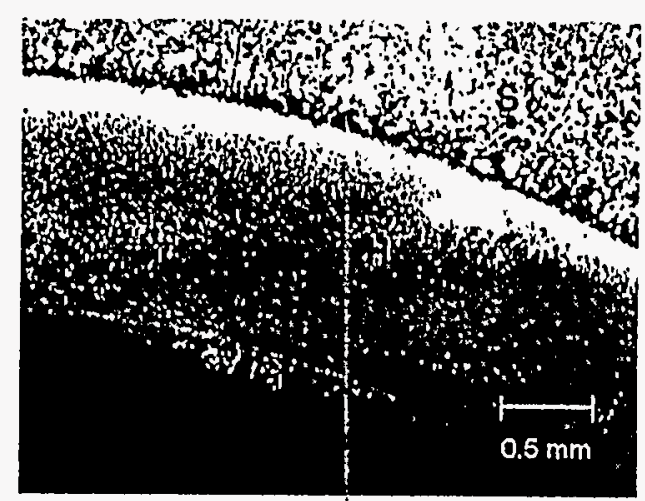

Laser-glazed surface of rall steel sample showing structure of base substrate material (S), heat-affected zone $(H)$ and "glazed" reglon (G) (etched). (b)

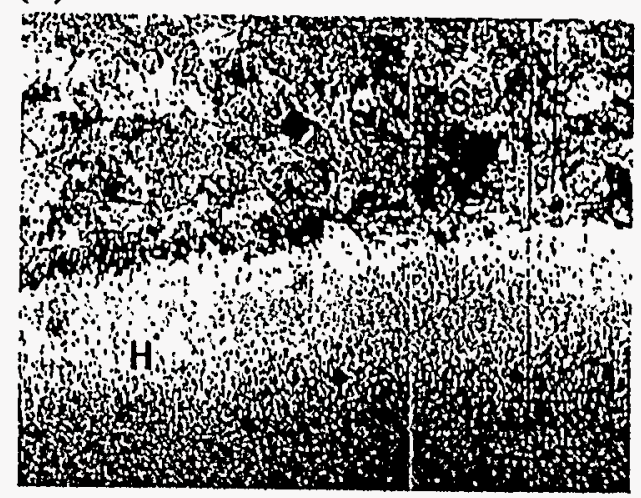

Tho samo sample as on the left showing Vickers hardness Impresslons in the substrate (HV 300) and the heal-affected zone (HV 840) made al the samo load (etched).

(c)

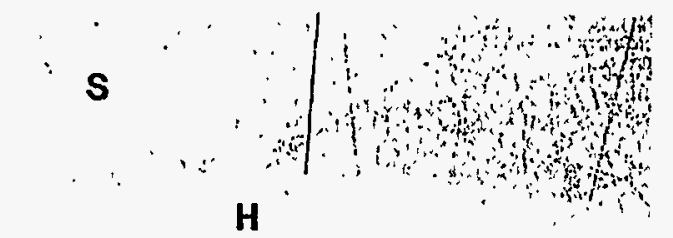

H

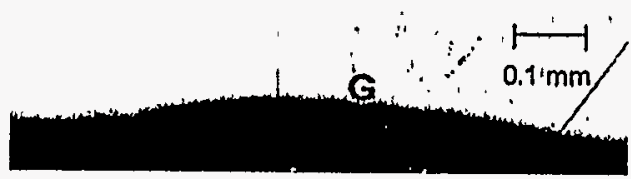

Unetched sample of laser-glazed rall steel surface,

showing the high integrity of the interfaces between the

substrate, heat-affected zone and "glazed" reglons.

Figure 7. Optical micrographs of cross section of the laser glazed region from preliminary treatments performed on the surface of a rail head. Figures (a) and (b) show the sample etched with Vilella's etchant. 


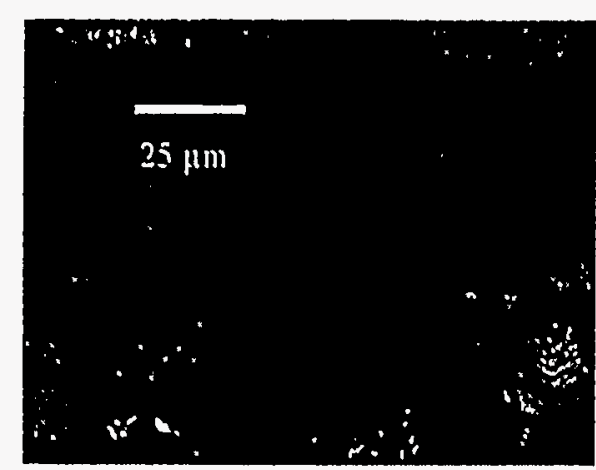

1080 (Rail) Steel Microstructure

Before Glazing $\left(\mathrm{H}_{\mathrm{V}}=250-300\right)$

and Substrate $1 \mathrm{~mm}$ beneath Glaze
Glazed Region

$\left(I_{V}\right.$ 689)

Untempered Martensite $\left(\mathrm{H}_{\mathrm{V}}\right.$ 1072)

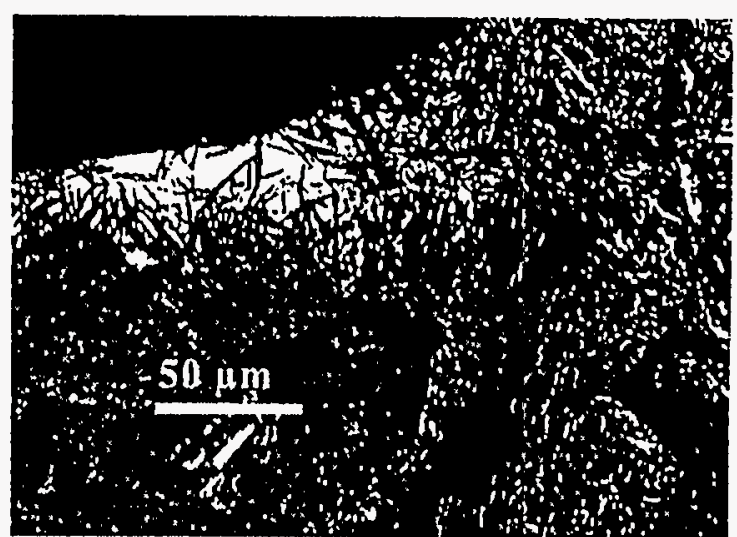

(b) Single Pass (e), $1 \mathrm{~cm} / \mathrm{s}$

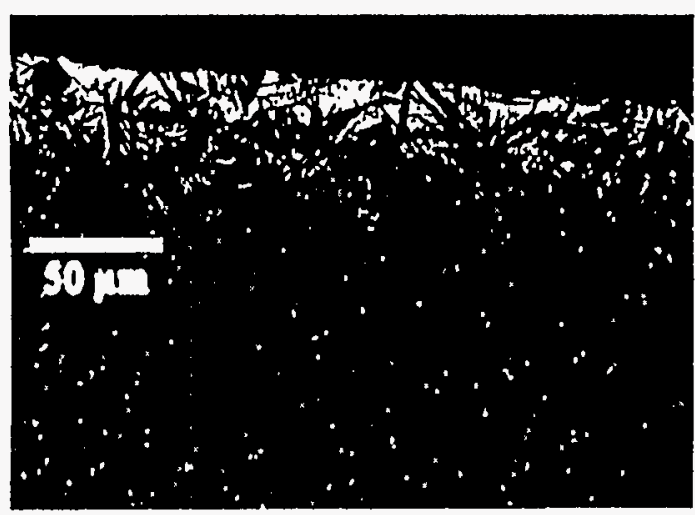

Glazed Layer $\left(\mathrm{H}_{\mathrm{V}}=655\right)$

I

Tèmpered Martensite $\left(\mathrm{H}_{\mathrm{V}}=470\right)$

(multiple pass of beam tempers structure)

Figure 8. Optical micrographs of the cross sections of laser treated AISI 1080 steel plates. Figure (a) is the untreated substrate region, (b) shows the microstructure of the glazed region from a multiple-pass overlapping glazing treatment, and (c) shows the microstructure of a single-pass treatment. Samples are etched with Nital. 


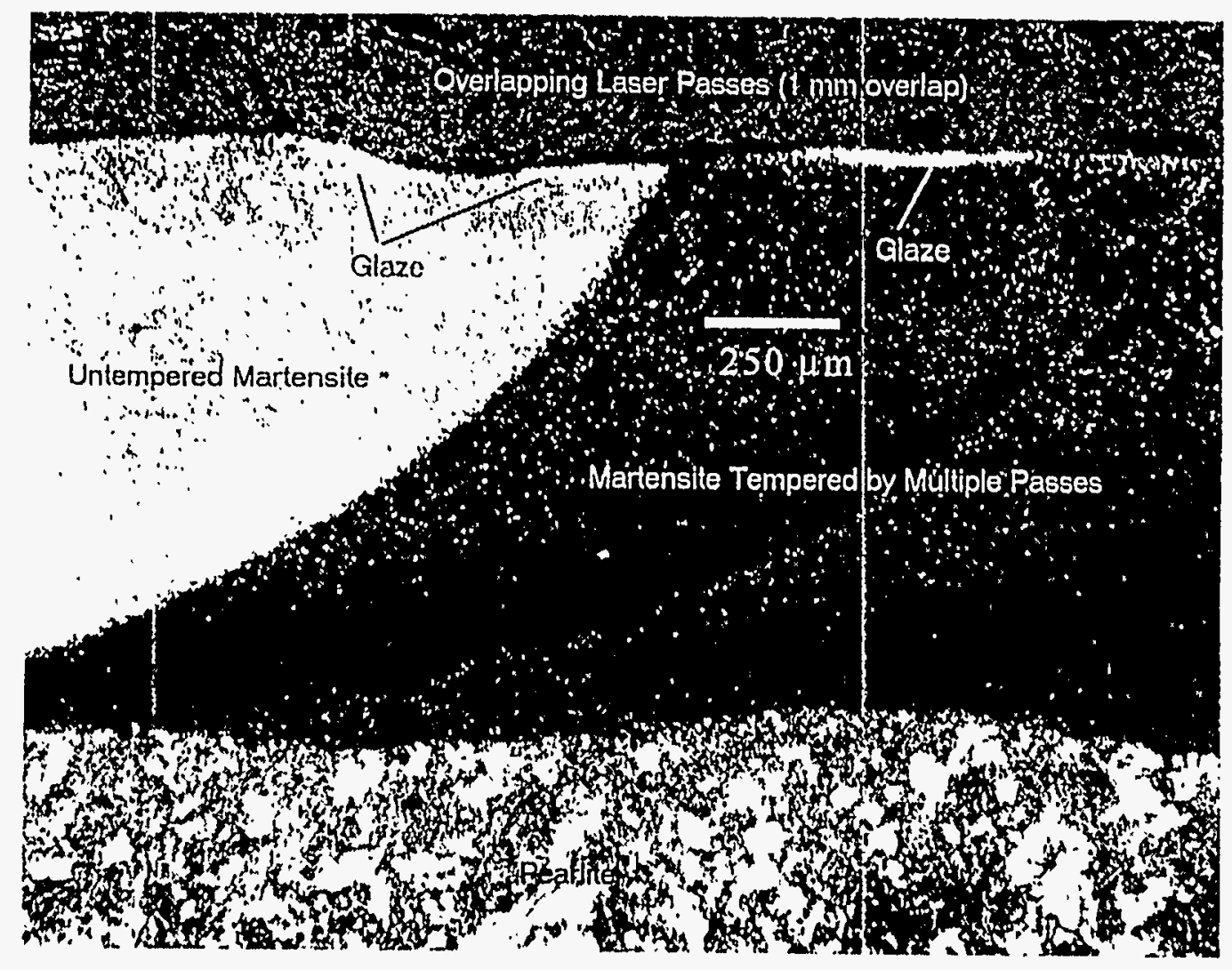

Figure 9. A micrograph of the cross section of a multiple-pass overlapping Nd:YAG laser treatment ( $944 \mathrm{~W}$ delivered power) using an elliptical ( $5 \mathrm{~mm}$ diameter) beam moving at $1 \mathrm{~cm} / \mathrm{s}$. The next-to-last pass and the last pass are shown. Heat from the last pass tempers the martensite in the next-to-last pass. The sample was etched with Nital. 
Coefficient of friction vs load for untreated and laser glazed rail steel

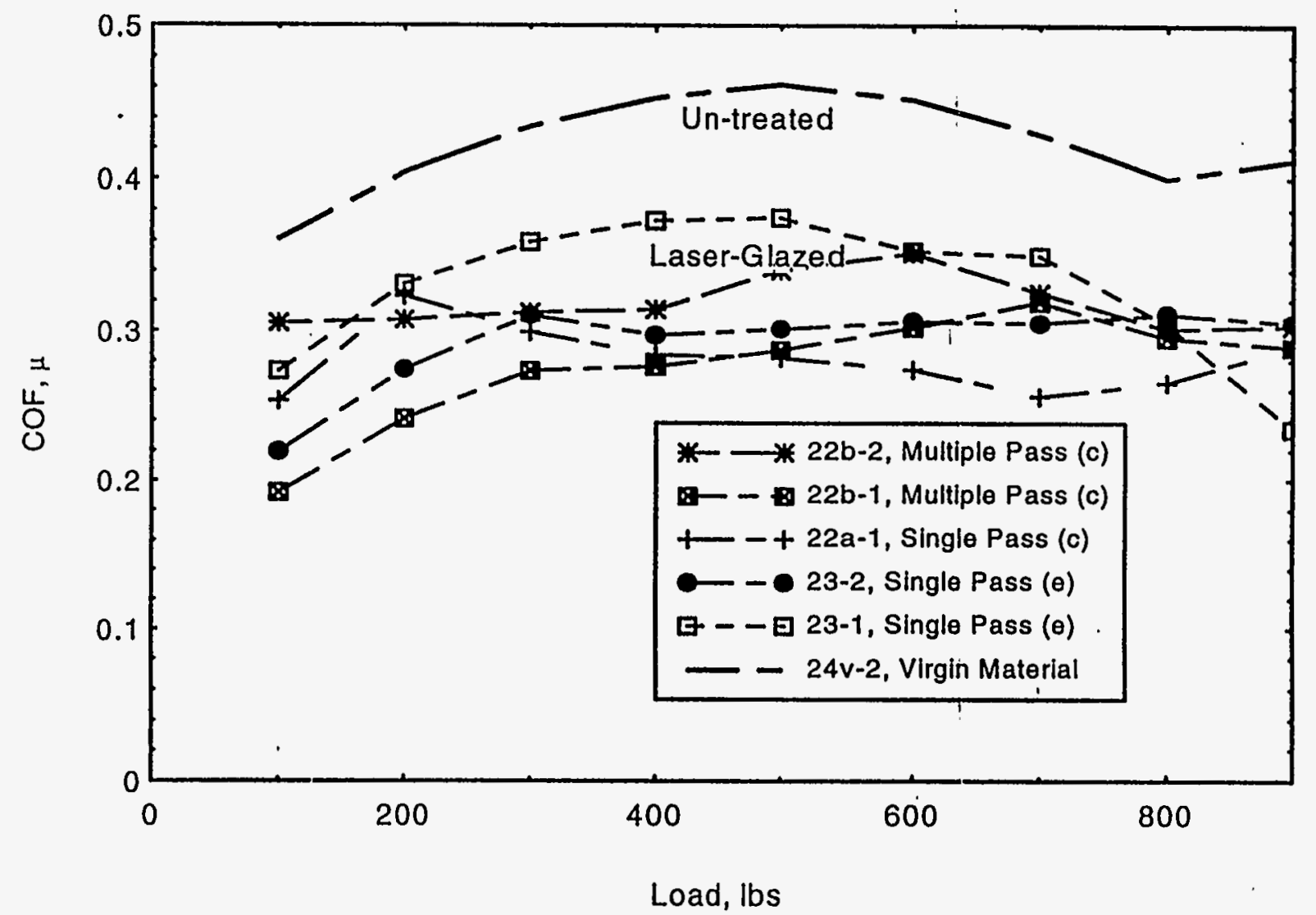

Figure 10. Measurements of the friction coefficient for laser-treated AISI 1080 steel samples, shown as a function of normal load in comparison with results typical of untreated control samples. The measurements were obtained using standard (ASTM G77-93) block-on-ring friction tests. 


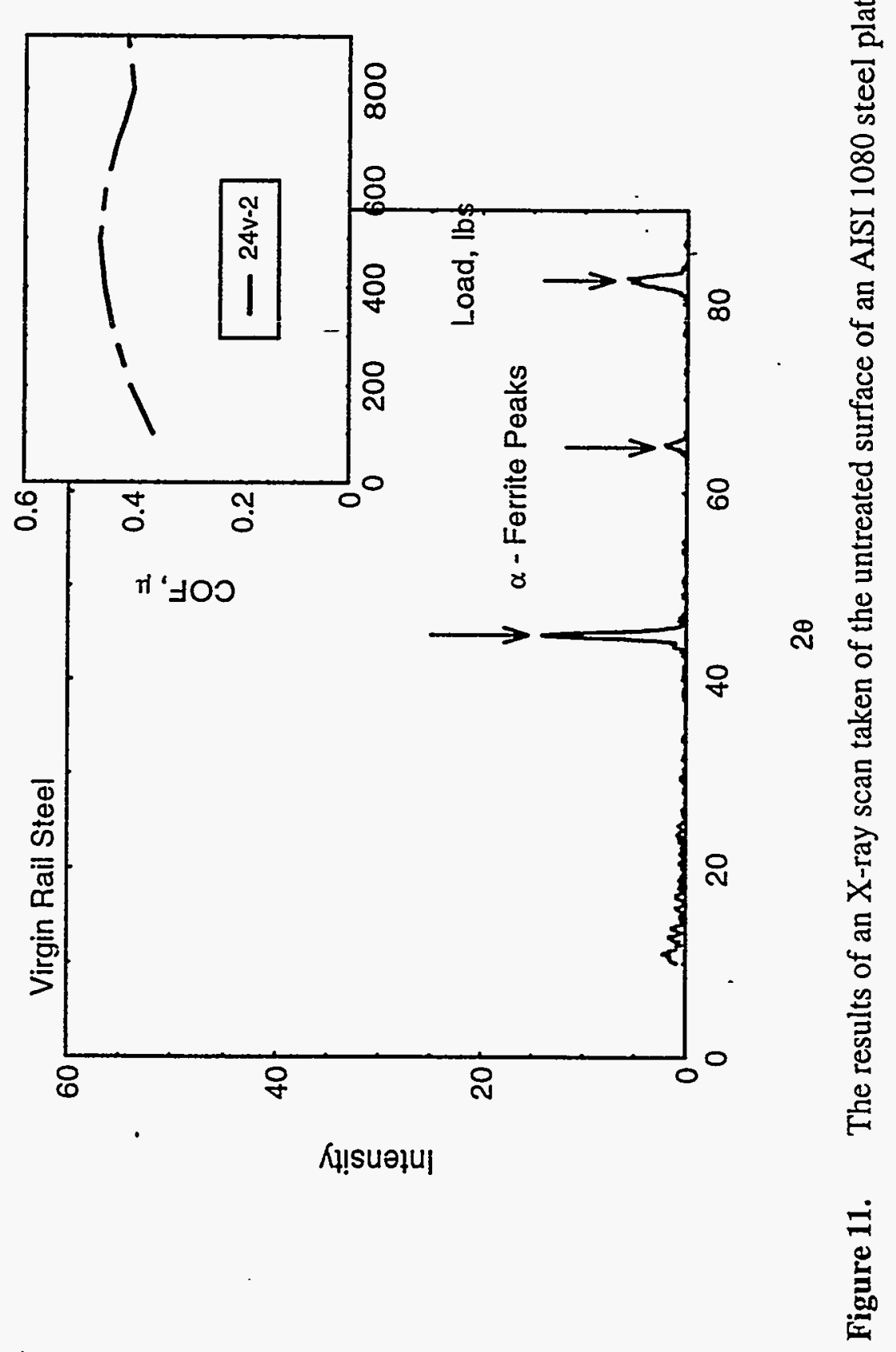




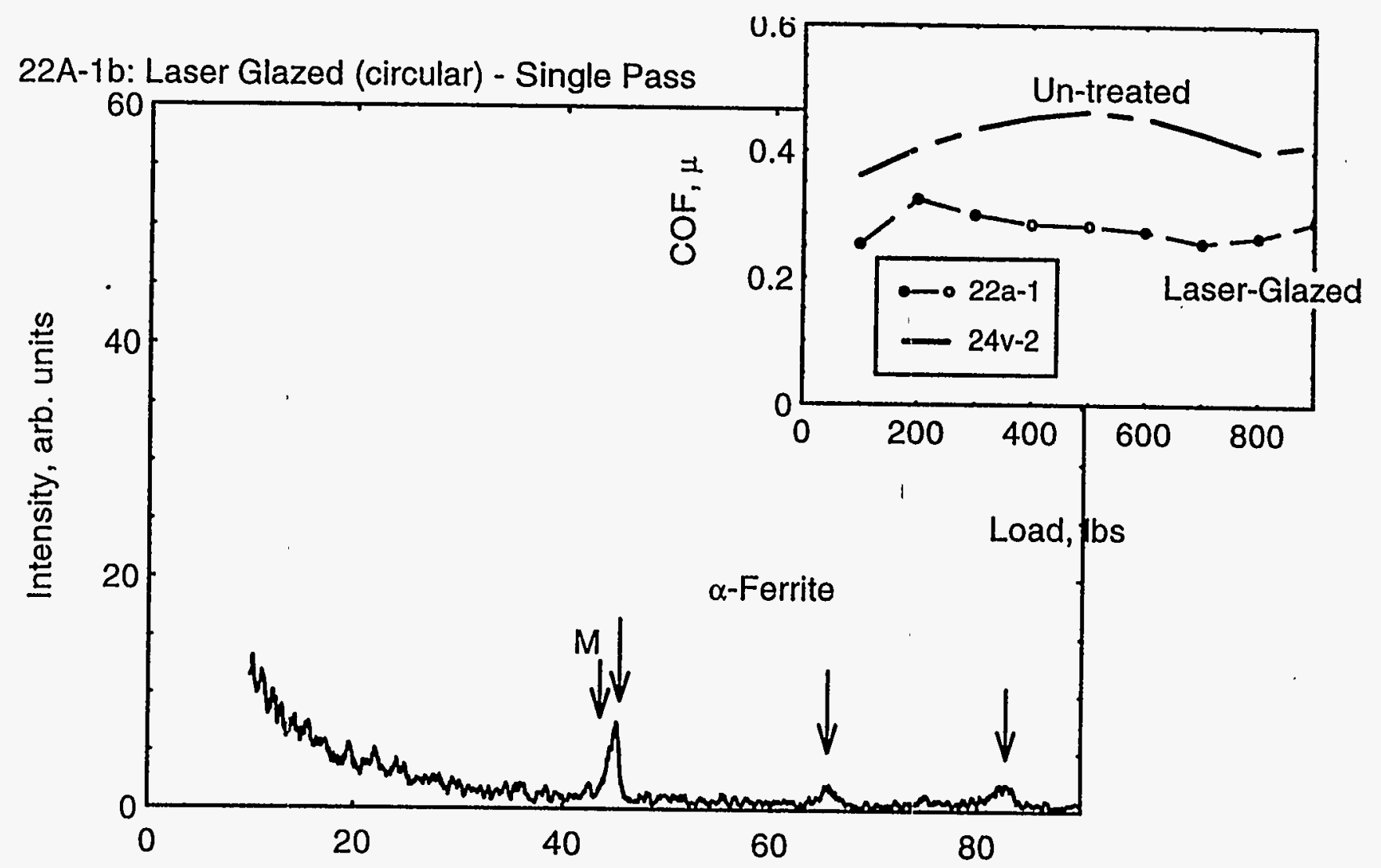

$2 \theta$

Figure 12. The results of an X-ray scan obtained from an AISI 1080 steel sample that received a single pass laser treatment with a circular beam $(2 \mathrm{~cm} / \mathrm{s})$. In addition to the $\alpha$-ferrite peaks also seen in the untreated sample, there are some diffuse scattering effects and the indication of a peak consistent with the presence of martensite $(M)$. 


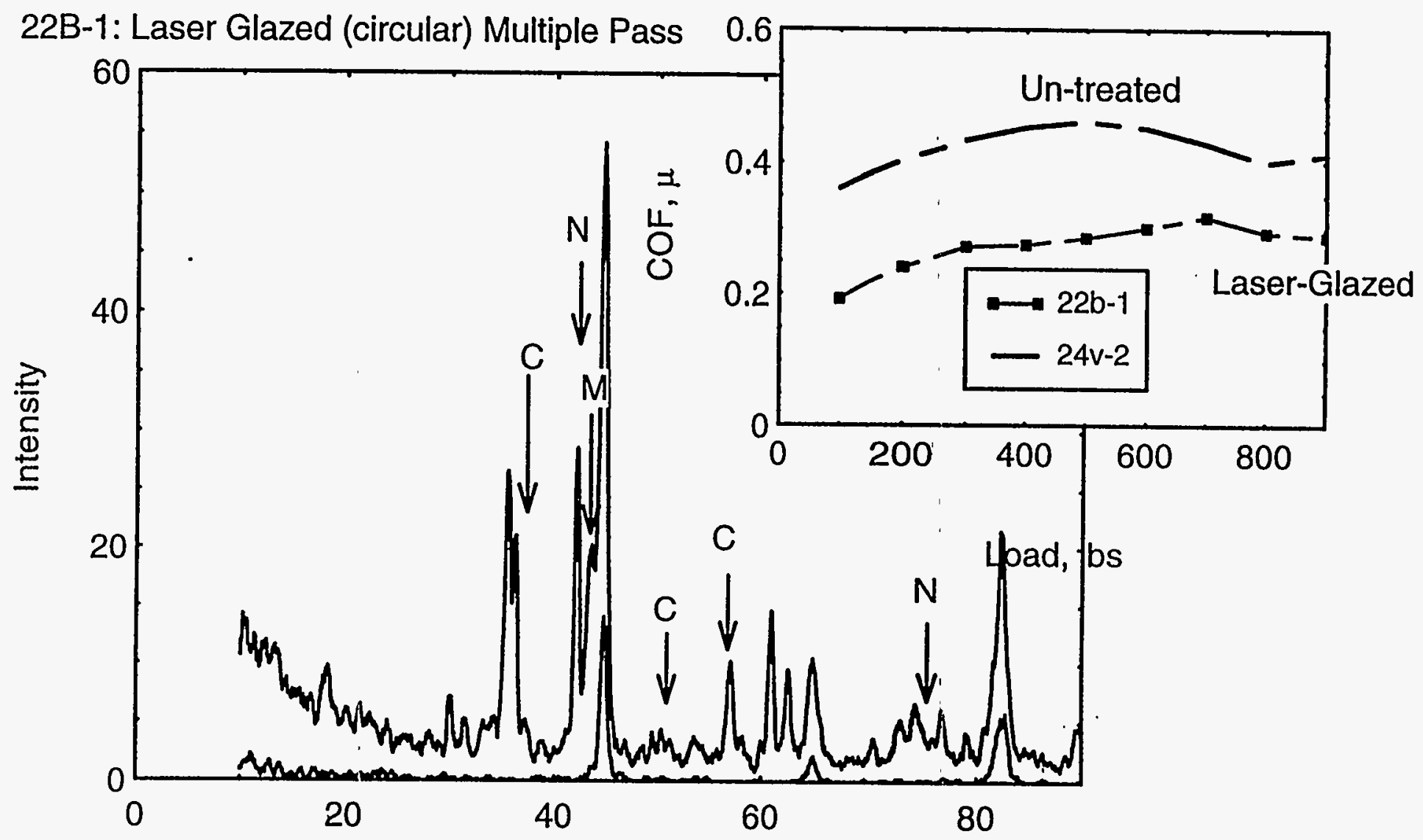

$2 \theta$

Figure 13. The $\mathrm{X}$-ray scan from a sample that received a multiple overlapping-pass laser treatment with a circular beam $(2 \mathrm{~cm} / \mathrm{s})$, shown along with the results of the scan from the untreated sample (Fig. 11). The $\alpha$-ferrite peaks are still apparent along with peaks consistent with the presence of martensite, cementite $(\mathrm{C})$, and $\mathrm{Fe}_{2} \mathrm{~N}(\mathrm{~N})$, as well as some diffuse scattering effects. A number of peaks could not be identified. 


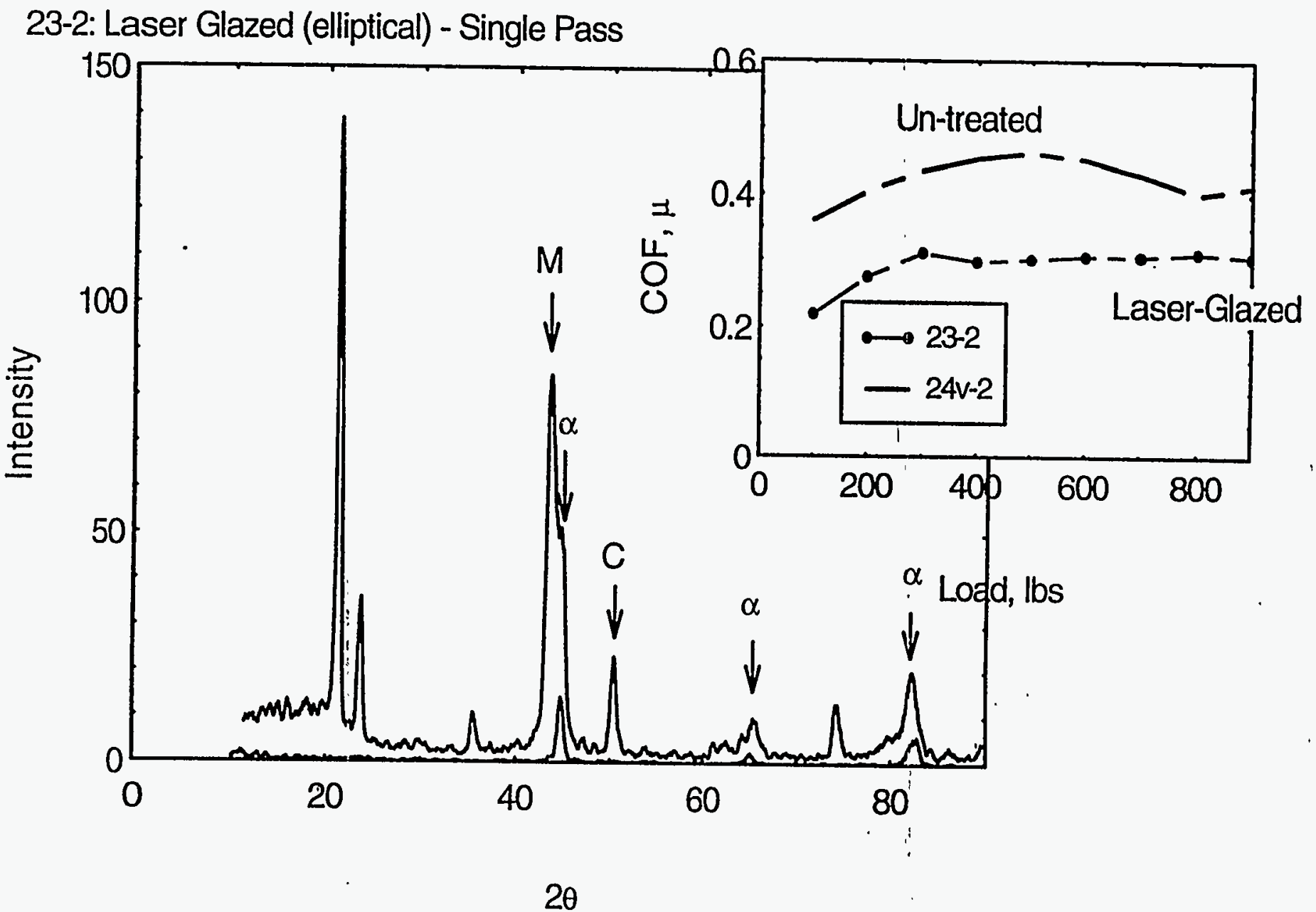

Figure 14. The results of an $\mathrm{X}$-ray scan of a sample that received a single pass laser treatment with an elliptical beam $(1 \mathrm{~cm} / \mathrm{s})$, shown with the scan from the untreated sample. Peaks consistent with $\alpha$-ferrite, cementite $(C)$, and martensite $(M)$ are indicated. A number of peaks could not be identified. 

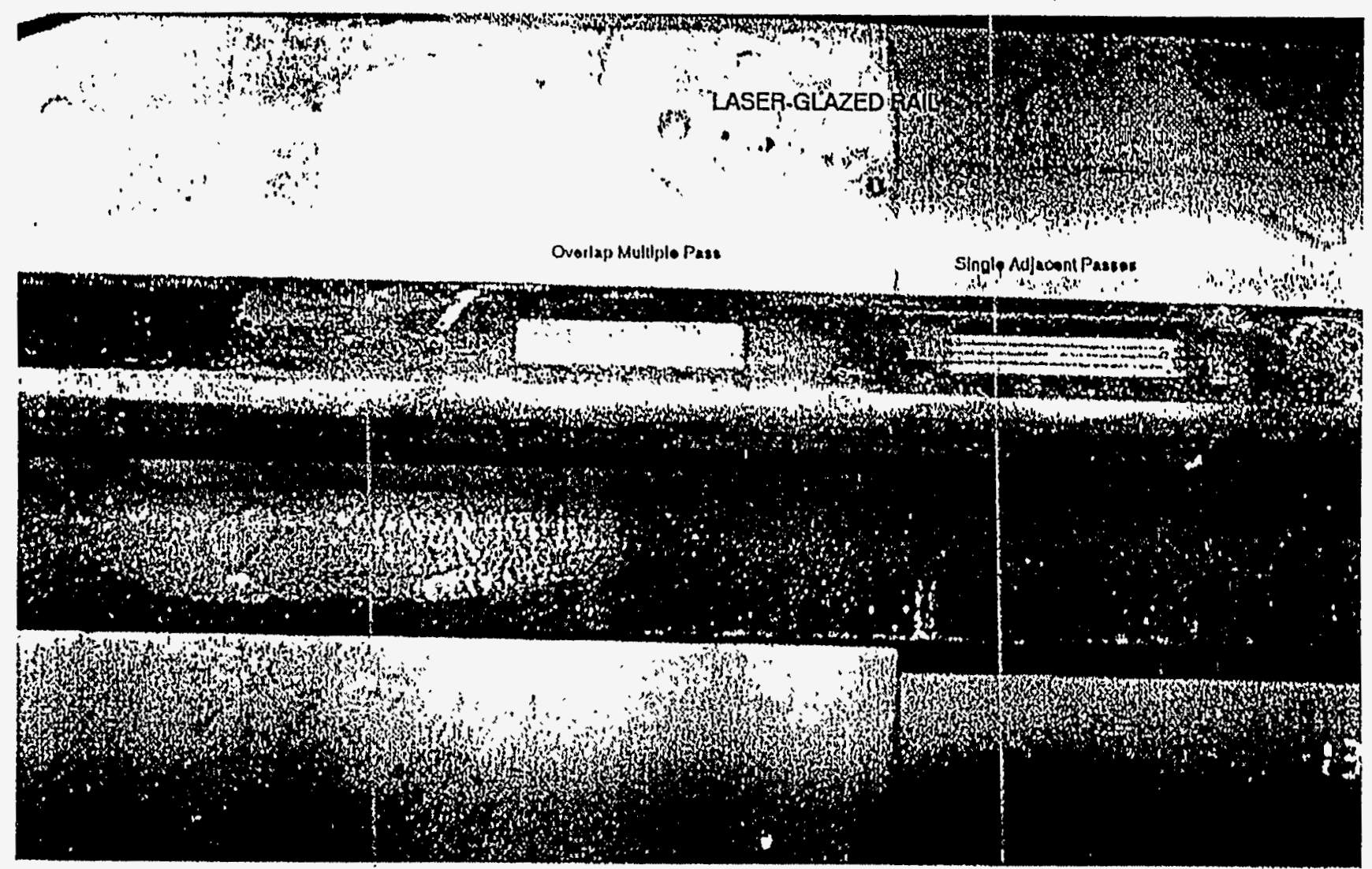

Iijgure 15. A photograph of a section of unused railroad rail that received two four-inch long laser glaze treatments on its top surface: a multiple overlapping pass treatment done with a circular beam (left), and a multiple pass treatment made up of single adjacent passes done with an elliptical beam (right). 

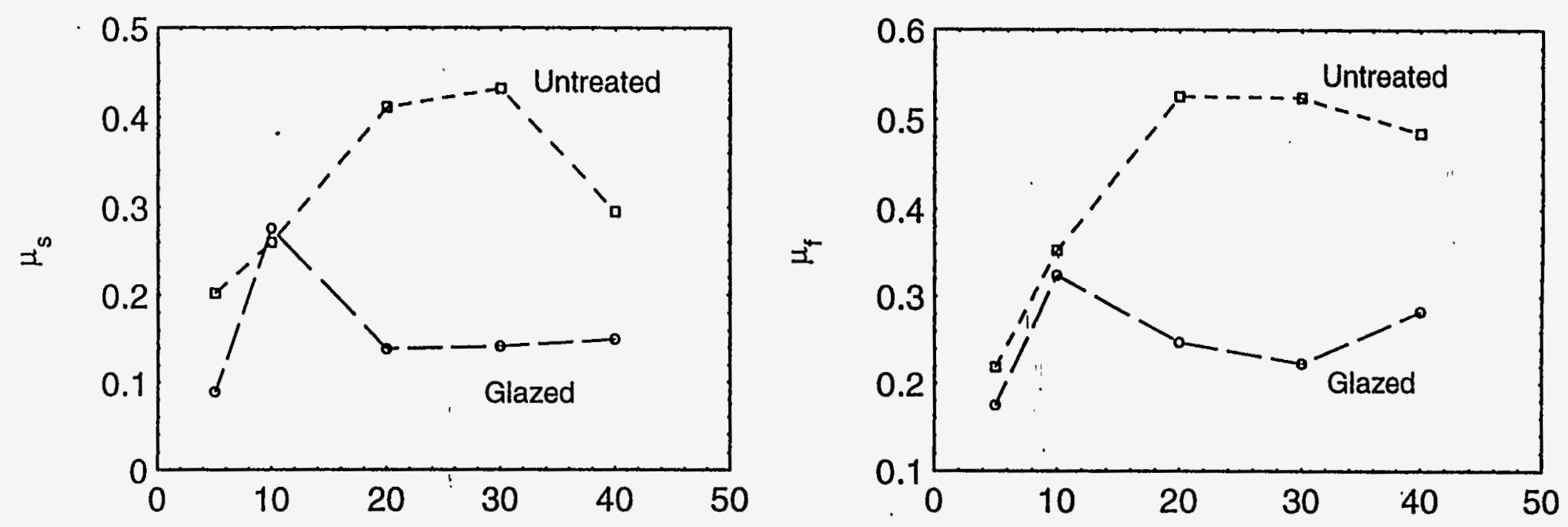

Normal Load, $10^{3} \mathrm{lbs}$

Normal Load, $10^{3} \mathrm{lbs}$

Figure 16. The results of friction measurements made at the AAR's Cyclic Rolling-sliding Wear Machine on a rail surface given a multiple overlapping pass treatment with a circular beam $(2 \mathrm{~cm} / \mathrm{s})$. Measurements of breakaway friction (left, $\mu_{s}$ ) and freely rotating friction (right, $\mu_{f}$ ) are shown in comparison with the results for untreated surfaces of the rail. 


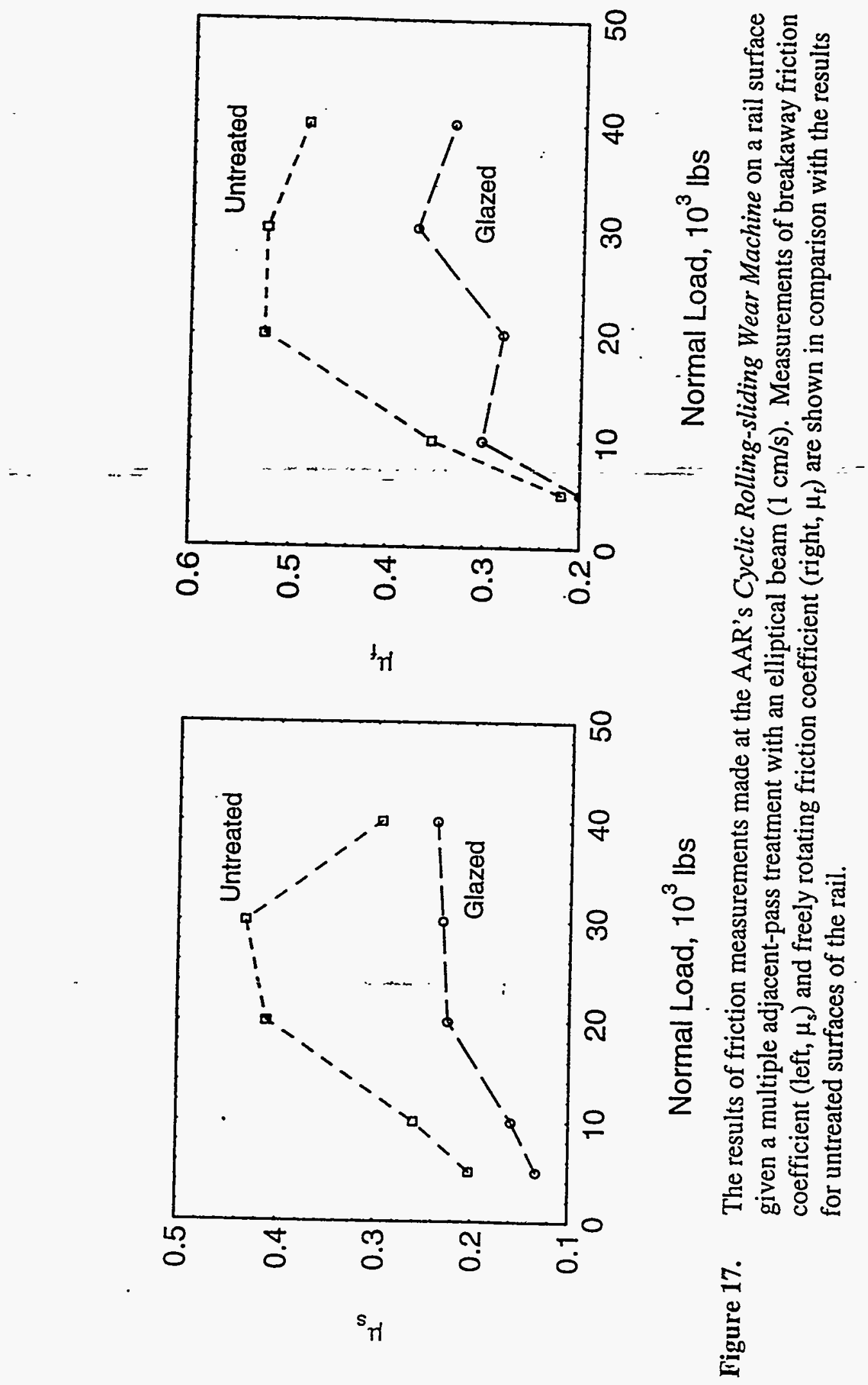

